\title{
Modulation of the Northern Winter Stratospheric EI Niño-Southern Oscillation Teleconnection by the PDO
}

\author{
JIAN RAO \\ Key Laboratory of Meteorological Disaster, Ministry of Education/Joint International Research Laboratory of Climate \\ and Environment Change/Collaborative Innovation Center on Forecast and Evaluation of Meteorological Disasters, \\ Nanjing University of Information Science and Technology, Nanjing, and State Key Laboratory of Numerical Modeling \\ for Atmospheric Sciences and Geophysical Fluid Dynamics, Institute of Atmospheric Physics, Chinese Academy of \\ Sciences, Beijing, China, and Fredy and Nadine Herrmann Institute of Earth Sciences, The Hebrew University of \\ Jerusalem, Edmond J. Safra Campus, Givat Ram Jerusalem, Israel

\section{CHAIM I. GARFINKEL} \\ Fredy and Nadine Herrmann Institute of Earth Sciences, The Hebrew University of Jerusalem, Edmond J. Safra Campus, \\ Givat Ram Jerusalem, Israel

\section{RONGCAI REN} \\ State Key Laboratory of Numerical Modeling for Atmospheric Sciences and Geophysical Fluid Dynamics, Institute of Atmospheric \\ Physics, Chinese Academy of Sciences, Beijing, and Key Laboratory of Meteorological Disaster, Ministry of Education/Joint \\ International Research Laboratory of Climate and Environment Change/Collaborative Innovation Center on Forecast and \\ Evaluation of Meteorological Disasters, Nanjing University of Information Science and Technology, Nanjing, China
}

(Manuscript received 30 January 2019, in final form 12 June 2019)

\begin{abstract}
Using the CMIP5 multimodel ensemble (MME) historical experiments, the modulation of the stratospheric El Niño-Southern Oscillation (ENSO) teleconnection by the Pacific decadal oscillation (PDO) is investigated in this study. El Niño (La Niña) significantly impacts the extratropical stratosphere mainly during the positive (negative) PDO in the MME. Although the composite tropical ENSO SST intensities are similar during the positive and negative PDO in models, the Pacific-North American (PNA) responses are only significant when the PDO and ENSO are in phase. The local SST anomalies in the North Pacific can constructively (destructively) interfere with the tropical ENSO forcing to influence the extratropical eddy height anomalies when the PDO and ENSO are in (out of) phase. The difference between the positive and negative PDO in El Niño or La Niña winters filters out the tropical SST forcing, permitting the deduction of the extratropical SST contribution to the atmospheric response. The composite shows that the cold (warm) SST anomalies in the central North Pacific associated with the positive (negative) PDO have a similar impact to that of the warm (cold) SST anomalies in the tropical Pacific, exhibiting a positive (negative) PNA-like response, enhancing (weakening) the upward propagation of waves over the western coast of North America. The composite difference between the positive and negative PDO in El Niño or La Niña winters, as well as in eastern Pacific ENSO or central Pacific ENSO winters, presents a highly consistent atmospheric response pattern, which may imply a linear interference of the PDO's impact with ENSO's.
\end{abstract}

\section{Introduction}

The significant response of the northern winter stratosphere to El Niño-Southern Oscillation (ENSO) has been widely reported in a large number of observational (Manzini et al. 2006; Garfinkel and Hartmann

Corresponding author: Jian Rao, raojian@nuist.edu.cn
2007, 2008; Free and Seidel 2009; Xie et al. 2012) and modeling (Sassi et al. 2004; García-Herrera et al. 2006; Taguchi and Hartmann 2006; Ineson and Scaife 2009; Bell et al. 2009; Cagnazzo and Manzini 2009; Cagnazzo et al. 2009; Garfinkel et al. 2012; Li and Lau 2013; Domeisen et al. 2015; Polvani et al. 2017; Rao and Ren 2017, 2018; Song and Son 2018; Domeisen et al. 2019; Weinberger et al. 2019) studies. The Aleutian low is 
generally deepened in El Niño winters and projects onto a strengthened Pacific-North America (PNA)-like response (Barnston and Livezey 1987). The deepened Aleutian low constructively interferes with the climatological stationary trough and leads to strengthened wave flux into the stratosphere and weakened polar vortices (Garfinkel and Hartmann 2008; Ineson and Scaife 2009; Bell et al. 2009; Garfinkel et al. 2010; Smith et al. 2010; Smith and Kushner 2012; Rao and Ren 2016a). Using a large model ensemble, some recent studies have shown that the polar stratospheric response to La Niña is generally a mirror image of that to El Niño (Garfinkel and Hartmann 2007; Iza et al. 2016; Garfinkel et al. 2018; Weinberger et al. 2019), although other studies have indicated that the enhanced planetary wave response to El Niño and the suppressed planetary wave response to La Niña is asymmetric (Manzini et al. 2006; Rao and Ren 2016a,b). The climatological wavenumber 1 is strengthened during El Niño winters, while the wavenumber 2 is intensified during La Niña winters (Taguchi and Hartmann 2006; Barriopedro and Calvo 2014).

According to the longitudes of the maximum sea surface temperature (SST) anomalies in the tropical Pacific, ENSO events can be divided into central Pacific (CP) ENSO events (Larkin and Harrison 2005; Ashok et al. 2007; Yu and Kim 2011) and east Pacific (EP) ENSO events (Larkin and Harrison 2005; Hurwitz et al. 2014; Domeisen et al. 2019). Some studies found that the deepening of the Aleutian low and the Northern Hemisphere polar stratosphere response is stronger for EP events (Yu and Kim 2011; Sung et al. 2014), while CP El Niño events lead to a southward and westward displacement of the anomalously low sea level pressure relative to EP Niño events (Garfinkel et al. 2013, 2018). No consensus on the stratospheric response to CP El Niño events has been reached, because of the difference in CP El Niño definitions, cases investigated, models used, and even experiment designs (Garfinkel et al. 2012; Graf and Zanchettin 2012; Xie et al. 2012; Hegyi et al. 2014; Hurwitz et al. 2014; Calvo et al. 2017). The combination of relatively few CP El Niño events and large atmospheric internal variability limits the robustness of conclusions as to the teleconnections of CP El Niño events (Deser et al. 2017). However, large experiment ensembles have shown similar stratospheric responses when identical SST anomalies are placed alternately in the eastern Pacific or central Pacific (Hegyi et al. 2014).

ENSO's impact on the northern winter stratosphere appears to be nonstationary (Hu et al. 2017; Yang et al. 2017; Domeisen et al. 2019): no robust connection between ENSO and the Arctic stratospheric vortex can be established if one only samples El Niño or La Niña events after 1979. This nonstationarity may be related to the flavor of El Niño events that have occurred, as CP El Niños occurred more frequently over this period than before (Calvo et al. 2017; Hu et al. 2017; Yang et al. 2017; Ayarzagüena et al. 2019; Domeisen et al. 2019). The convective center over the equatorial Pacific during El Niño winters, as well as the extratropical height response, has shifted (e.g., Meehl and Teng 2007; Wittenberg 2009; Deser et al. 2010; Zhou et al. 2014). The unstable ENSO-stratosphere relationship may also be unforced and reflect sampling uncertainty from the short observations (Domeisen et al. 2019).

Another explanation for the observed nonstationarity of ENSO's impact is the interference of thermal forcing from other ocean basins. For example, the intensity and spatial pattern of the PNA teleconnection have been reported to be destructively modulated by the diabatic heating forcing over the tropical Indian and Atlantic Oceans (Annamalai et al. 2007; Fletcher and Kushner 2011; Rao and Ren 2016a, 2018; Zhou et al. 2018). The internal variability of the atmosphere-ocean system in the North Pacific may also lead to nonstationarity of stratospheric ENSO teleconnections (Gershunov and Barnett 1998; López-Parages et al. 2015, 2016; Newman et al. 2016; Ayarzagüena et al. 2019). As the principal empirical orthogonal function (EOF) of the extratropical Pacific SST (Zhang et al. 1997; Newman et al. 2003, 2016), the Pacific decadal oscillation (PDO) has been reported to influence the stratosphere (Jadin et al. 2010; Hurwitz et al. 2012; Mills and Walsh 2013; Woo et al. 2015; Kren et al. 2016; Hu and Guan 2018).

Recent studies have indicated that the PDO is not an independent oceanic phenomenon, but mainly forced by the tropical Pacific SST (Newman et al. 2003, 2016; Schneider and Cornuelle 2005; Shakun and Shaman 2009). The combination of ENSO with other physical processes can well reconstruct the PDO index with a first-order autoregressive model (Schneider and Cornuelle 2005; Newman et al. 2003, 2016). Those physical processes include North Pacific atmosphereocean interactions and coupled variability (Alexander 2010; Newman et al. 2016), atmospheric stochastic forcing from the Aleutian low (Seager et al. 2001; Kwon and Deser 2007; Frankignoul and Sennéchael 2007), and atmospheric teleconnections (Newman et al. 2003; Chhak et al. 2009; Shakun and Shaman 2009; Kwon et al. 2010; Newman et al. 2016).

The influence of the PDO on surface climate has been widely documented in many studies (e.g., Zhang et al. 1997; Mantua and Hare 2002; Alexander et al. 2006; Deser et al. 2012). The positive PDO phases are related to warmer temperatures over the western coast of the North American continent and cooler temperatures over the eastern United States (Mantua et al. 1997; 
Minobe 1997). The Gulf of Alaska and southwestern United States are wetter during positive PDO phases (Dettinger et al. 2001; Dai 2013; Mills and Walsh 2013). In addition to the individual impact of PDO on regional climate, the combined impact of ENSO and PDO has also been explored in recent studies ( $\mathrm{Yu}$ and Zwiers 2007; Veettil et al. 2014; Xiao et al. 2015; Wu and Mao 2016). The impacts of ENSO on Alaskan wintertime temperature; Rocky Mountain fire; European, Mexican, and Pacific-American climate; and the northern Andean glaciers are different between positive and negative PDO phases (Papineau 2001; Schoennagel et al. 2005; Brönnimann et al. 2006; Pavia et al. 2006; Yu and Zwiers 2007; Veettil et al. 2014). The European wintertime rainfall response to El Niño is stronger and more significant during the positive PDO than during the negative PDO (Zanchettin et al. 2008). Similarly, the positive correlations between ENSO and South China spring rainfall are largely enhanced when the PDO and ENSO are in phase (Xiao et al. 2015; Wu and Mao 2016).

Similar to the atmospheric response to El Niño, the positive PDO usually deepens the Aleutian low and strengthens the subtropical jet (Bond and Harrison 2000; Frankignoul and Sennéchael 2007; Hurwitz et al. 2012; Mills and Walsh 2013; Woo et al. 2015; Kren et al. 2016), whereas the negative PDO, on average, weakens the Aleutian low and inhibits planetary wave propagation into the stratosphere (Limpasuvan et al. 2005; Nishii et al. 2010). Using the National Centers for Environmental Prediction-National Center for Atmospheric Research (NCEP-NCAR) reanalysis, Jadin et al. (2010) provided evidence for a relationship between the December PDO index and the January wave activity over the Eurasian continent. Woo et al. (2015) found that weak stratospheric polar vortex events are observed to occur more frequently during positive PDO phases than during negative PDO phases.

The shortness of the observational record limits the robustness of the PDO-stratosphere relationship, although numerical simulations by a wide range of models have indicated that the PDO impacts the stratosphere (Hurwitz et al. 2012; Kren et al. 2016). However, Hurwitz et al. (2012) used an AGCM with prescribed SST that does not allow for the PDO to respond to stochastic atmospheric variability as the observed PDO (Newman et al. 2016). Kren et al. (2016) used a coupled model, but only 200 years of model data were analyzed and the number of PDO cases is still not large enough. If we consider the contamination of the PDO with ENSO, the case number in Kren et al. (2016) and Calvo et al. (2017) is even smaller.

The goal of this study is to investigate the modulation of the ENSO-stratosphere relationship by the PDO with a large multimodel ensemble (MME). In this study, we will provide model evidence to answer the following questions: 1) Is there any relationship between ENSO and the stratosphere when the number of ENSO cases is several hundred large to decrease the sampling bias? 2) If so, is there any significant difference between the northern winter stratospheric response to ENSO when the ENSO cases are resampled according to the PDO phase? 3) Does a specific PDO phase favor the occurrence of an ENSO type (EP or CP) but inhibit the occurrence of the other type (CP or EP)? If so, can the ENSO type preference explain the nonstationarity of ENSO's impact on the northern winter stratosphere?

This paper consists of seven sections. Following the introduction in section 1 , section 2 describes the data and methodology. Section 3 briefly examines the reproducibility of the tropospheric and stratospheric ENSO teleconnection by the CMIP5 MME. The modulation of the ENSO SST pattern by the PDO is presented in section 4 . The stratospheric responses to different ENSO and PDO configurations in the CMIP5 MME, the related dynamics, and relationship between ENSO types and the PDO are provided in sections 5 and 6 . Finally, a summary and discussion are presented in section 7.

\section{Data and methodology}

\section{a. Atmospheric reanalysis and model data}

The NCEP-NCAR Reanalysis 1 covering the period 1948-2017 (Kalnay et al. 1996) is employed to verify the reproducibility of ENSO teleconnections by the CMIP5 MME. We also used other modern reanalyses (MERRA and ERA-Interim) and results are similar (not shown). The SSTs used to obtain the spatial pattern and time series of the observed PDO and ENSO are extracted from the Hadley Centre Sea Ice and Sea Surface Temperature dataset (HadISST; Rayner et al. 2003).

Table 1 lists the 14 high-top CMIP5 models considered in this study with an atmospheric top above $1 \mathrm{hPa}$. The first CMIP5 model, CESM1-WACCM developed by NCAR, has been widely used to study impacts of the solar cycle (Marsh et al. 2007; Matthes et al. 2010), geoengineering (Tilmes et al. 2009), equatorial stratospheric quasi-biennial oscillation (QBO) (Garfinkel and Hartmann 2010; Garfinkel et al. 2010), and especially ENSO (Calvo et al. 2009; Xie et al. 2012; Rao and Ren 2016b,c, 2018; Ren et al. 2017) on the northern winter stratospheric polar vortex and climate change. Other stratosphere-resolving CMIP5 models in this study are nearly the same as in Charlton-Perez et al. (2013) and Calvo et al. (2017). As the ENSO modes largely deviate 
TABLE 1. The stratosphere-resolving CMIP5 models used in this study. The total time length of the multimodel ensemble (MME) is 2164 years.

\begin{tabular}{|c|c|c|c|c|c|}
\hline Model & $\begin{array}{l}\text { Affiliation and } \\
\text { nationality }\end{array}$ & Time span & $\begin{array}{l}\text { Horizontal resolution } \\
\quad(\text { lat } \times \text { lon })\end{array}$ & Top (No. of levels) & Reference \\
\hline CESM1-WACCM & $\begin{array}{l}\text { NSF-DOE-NCAR, } \\
\text { United States }\end{array}$ & 1850-2005 & F19 $(96 \times 144)$ & $5.1 \times 10^{-6} \mathrm{hPa}(\mathrm{L} 66)$ & Marsh et al. 2013 \\
\hline CMCC-CESM & CMCC, Italy & 1850-2005 & F19 $(96 \times 144)$ & $0.01 \mathrm{hPa}(\mathrm{L} 39)$ & Fogli and Iovino 2014 \\
\hline CMCC-CMS & CMCC, Italy & 1850-2005 & T63 $(96 \times 192)$ & $0.01 \mathrm{hPa}(\mathrm{L} 95)$ & Davini et al. 2014 \\
\hline GFDL CM3 & $\begin{array}{l}\text { NOAA GFDL, } \\
\text { United States }\end{array}$ & 1860-2005 & $\mathrm{C} 48(90 \times 144)$ & 86.4 km (L48) & Donner et al. 2011 \\
\hline HadGEM2-CC & $\begin{array}{l}\text { Met Office, United } \\
\text { Kingdom }\end{array}$ & 1860-2005 & N96 $(144 \times 192)$ & 85 km (L60) & Martin et al. 2011 \\
\hline IPSL-CM5A-LR & IPSL, France & 1850-2005 & $1.25 \times 2.5(144 \times 144)$ & 70 km (L39) & Dufresne et al. 2013 \\
\hline IPSL-CM5A-MR & IPSL, France & 1850-2005 & $1.875 \times 3.75(96 \times 96)$ & 70 km (L39) & Dufresne et al. 2013 \\
\hline IPSL-CM5B-LR & IPSL, France & $1850-2005$ & $1.875 \times 3.75(96 \times 96)$ & $70 \mathrm{~km}(\mathrm{~L} 39)$ & Dufresne et al. 2013 \\
\hline MIROC-ESM & $\begin{array}{l}\text { CCSR/NIES-AORI/ } \\
\text { UT-JAMSTEC, Japan }\end{array}$ & 1850-2005 & $\mathrm{T} 42(64 \times 128)$ & $0.0036 \mathrm{hPa}(\mathrm{L} 80)$ & Watanabe et al. 2011 \\
\hline $\begin{array}{l}\text { MIROC-ESM- } \\
\text { CHEM }\end{array}$ & $\begin{array}{l}\text { CCSR/NIES-AORI/ } \\
\text { UT-JAMSTEC, Japan }\end{array}$ & 1850-2005 & T42 $(64 \times 128)$ & $0.0036 \mathrm{hPa}(\mathrm{L} 80)$ & Watanabe et al. 2011 \\
\hline MPI-ESM-LR & MPI, Germany & 1850-2005 & T63 $(96 \times 192)$ & $0.01 \mathrm{hPa}(\mathrm{L} 47)$ & Giorgetta et al. 2013 \\
\hline MPI-ESM-MR & MPI, Germany & 1850-2005 & T63 $(96 \times 192)$ & $0.01 \mathrm{hPa}(\mathrm{L} 95)$ & Giorgetta et al. 2013 \\
\hline MPI-ESM-P & MPI, Germany & 1850-2005 & T63 $(96 \times 192)$ & $0.01 \mathrm{hPa}(\mathrm{L} 47)$ & Giorgetta et al. 2013 \\
\hline MRI-CGCM3 & MRI, Japan & 1850-2005 & TL159 $(160 \times 320)$ & $0.01 \mathrm{hPa}(\mathrm{L} 48)$ & Yukimoto et al. 2012 \\
\hline
\end{tabular}

from the observations in NASA GISS high-top models (Rao and Ren 2014; Rao et al. 2015) that were analyzed by Charlton-Perez et al. (2013) and Hurwitz et al. (2014), those models are not included in our composite study. In addition, the CCCma models that are used in Calvo et al. (2017) have a model top at $1 \mathrm{hPa}$, which is also excluded in our study. The experiment sizes in different models are also different for every scenario, but the historical runs are available for all of the 14 models. The first historical simulation (Taylor et al. 2012) forced by all forcings (i.e., greenhouse gas concentrations, ozone depletion, land uses, aerosols, and solar cycles) are available for all of the 14 high-top models. The GFDLCM3 and HadGEM2-CC models provided the simulation data during 1860-2005, 10 years shorter than other models that were integrated from 1850 to 2005. References for these models are also included in Table 1, and the configuration for each model can be found in those references.

\section{b. Data processing and methods}

We first compute the monthly mean seasonal cycle and long-term trend of each variable over the period over which data are available for each data source (e.g., 1948-2017 for reanalysis), and then subtract this longterm trend and seasonal climatology from its monthly mean raw fields to produce anomalies. Considering that the stratospheric climatology and the long-term trend may be different in CMIP5 models and in the reanalysis, the anomaly field for any variable and the subtraction of its long trend are separately computed for each data source. Finally, the 14 historical runs constituting the CMIP5 MME are concatenated in a fixed order (i.e., from the first model, CESM1-WACCM, to the last model, MRI-CGCM3; see Table 1) to construct a 2164-yr dataset. This large sample size of ENSO cases from the CMIP5 MME helps ensure a robust composite result.

After subtracting the long-term trend and the seasonal cycle from the SST raw field, three ENSO indices (Niño-3, Niño-4, and Niño-3.4) are calculated as their area-weighted SST anomalies. El Niño events are identified when the winter-mean (December-February) Niño-3.4 $\left(5^{\circ} \mathrm{S}-5^{\circ} \mathrm{N}, 170^{\circ}-120^{\circ} \mathrm{W}\right)$ index exceeds $0.5 \mathrm{~K}$, and La Niña events are identified when the winter-mean Niño-3.4 index falls below $-0.5 \mathrm{~K}$. ENSO events are further categorized into $\mathrm{EP}$ and $\mathrm{CP}$ flavors by comparing the Niño-3 and Niño-4 indices (Hurwitz et al. 2014). EP El Niño events are identified when the Niño-3 $\left(5^{\circ} \mathrm{S}-5^{\circ} \mathrm{N}\right.$, $\left.150^{\circ}-90^{\circ} \mathrm{W}\right)$ index is larger than the Niño- $4\left(5^{\circ} \mathrm{S}-5^{\circ} \mathrm{N}\right.$, $160^{\circ} \mathrm{E}-150^{\circ} \mathrm{W}$ ) index and the Niño-3.4 index exceeds $0.5 \mathrm{~K}$, whereas CP El Niño events are identified when the Niño-4 index is larger than the Niño-3 index and the Niño-3.4 index also exceeds 0.5 K. Similarly, EP La Niña events are identified when the Niño-3 index is below the Niño-4 index and the Niño-3.4 index falls below $-0.5 \mathrm{~K}$, whereas CP La Niña events are identified when the Niño-4 index is below the Niño-3 index and the Niño34 index also falls below $-0.5 \mathrm{~K}$. The PDO mode (Mantua et al. 1997; Zhang et al. 1997; Newman et al. 2016) is the leading EOF of SST anomalies in the extratropical Pacific sector (poleward of $20^{\circ} \mathrm{N}$ ), and the corresponding 

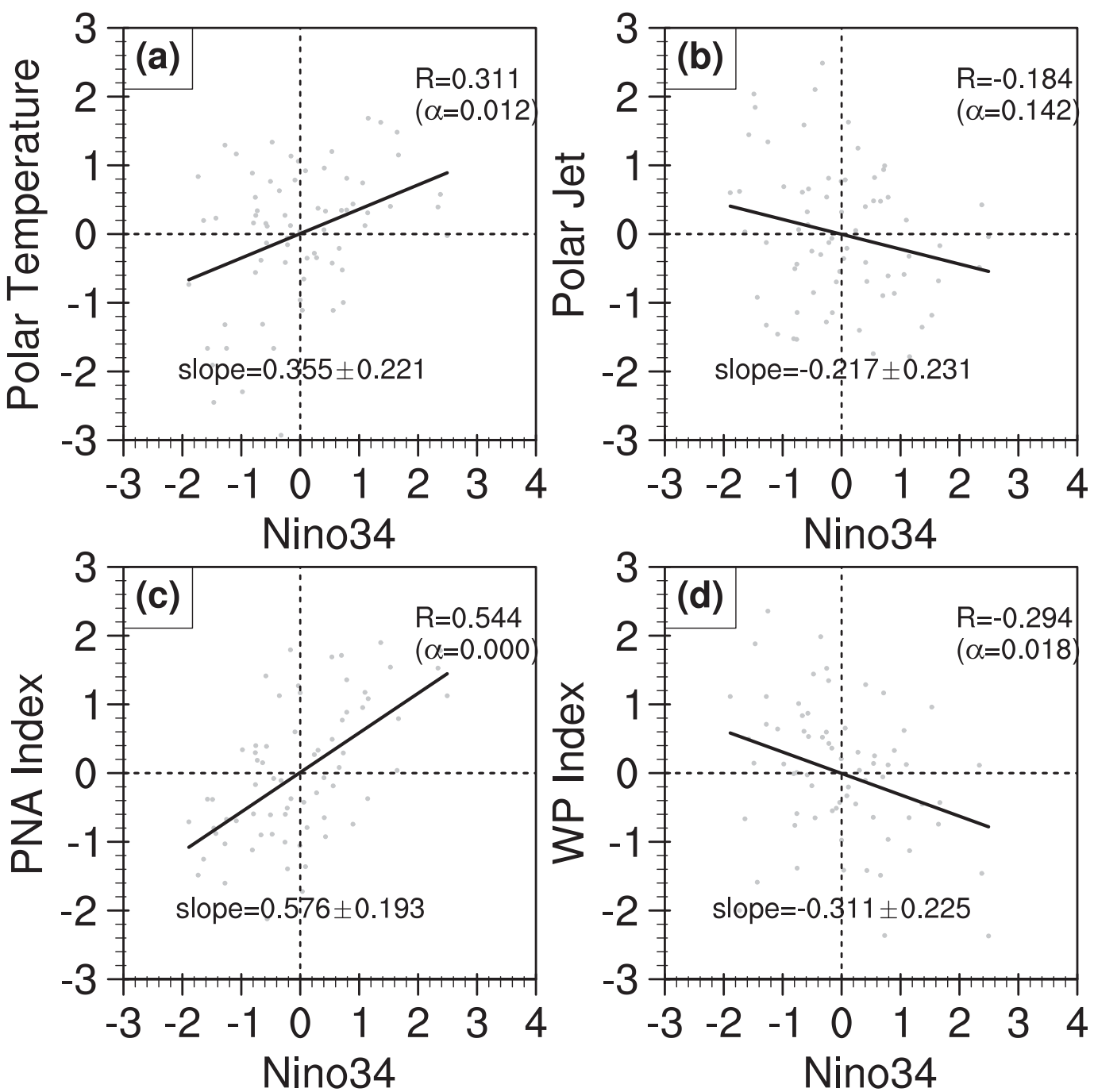

FIG. 1. Scatterplots of the winter Niño-3.4 $\left(5^{\circ} \mathrm{S}-5^{\circ} \mathrm{N}, 170^{\circ}-120^{\circ} \mathrm{W} ; \mathrm{K}\right)$ index vs four indicators (nondimensional): (a) the normalized winter $T_{\text {pole }}\left(70-10 \mathrm{hPa}, 60^{\circ}-90^{\circ} \mathrm{N}\right)$, (b) the normalized winter $U_{\text {pole }}\left(50-10 \mathrm{hPa}, 65^{\circ}-75^{\circ} \mathrm{N}\right)$, (c) the normalized winter PNA index, and (d) the normalized winter WP index. The black lines present the linear relationships between the winter Niño-3.4 index and each of the four indicators. The correlation coefficient, its significance level $\alpha$, and the estimated slope interval at the $95 \%$ confidence level are also shown for each plot. The winter Niño-3.4 index is calculated based on the HadISST data, and the four circulation indices are extracted from NCEP-NCAR.

normalized time series is defined as the PDO index. We regressed the SST anomalies against the PDO index time series to represent the PDO SST spatial pattern. The positive (negative) PDO phases are identified when the PDO index is above 0.5 (below -0.5) times its standard deviation.

\section{Reproducibility of the stratospheric ENSO teleconnection in the CMIP5 MME}

The scatterplots of the Niño-3.4 index from HadISST versus the stratospheric polar cap temperature $T_{\text {pole }}$ (mass weighted between 70 and $10 \mathrm{hPa}$; area weighted between $60^{\circ}$ and $90^{\circ} \mathrm{N}$ ), stratospheric circumpolar westerly jet $U_{\text {pole }}$ (mass weighted between 50 and $10 \mathrm{hPa}$; area weighted between $65^{\circ}$ and $75^{\circ} \mathrm{N}$ ), PNA index, and western Pacific (WP) index (Wallace and Gutzler 1981) from the NCEP-NCAR reanalysis (19482016) are shown in Fig. 1. Results are similar if we examine the period 1979-2016 in the ERA-Interim and MERRA reanalyses (not shown). The stratospheric polar cap temperature tends to be anomalously warm in El Niño winters and anomalously cold in La Niña winters (Fig. 1a). The linear fitting between ENSO and $T_{\text {pole }}$ 

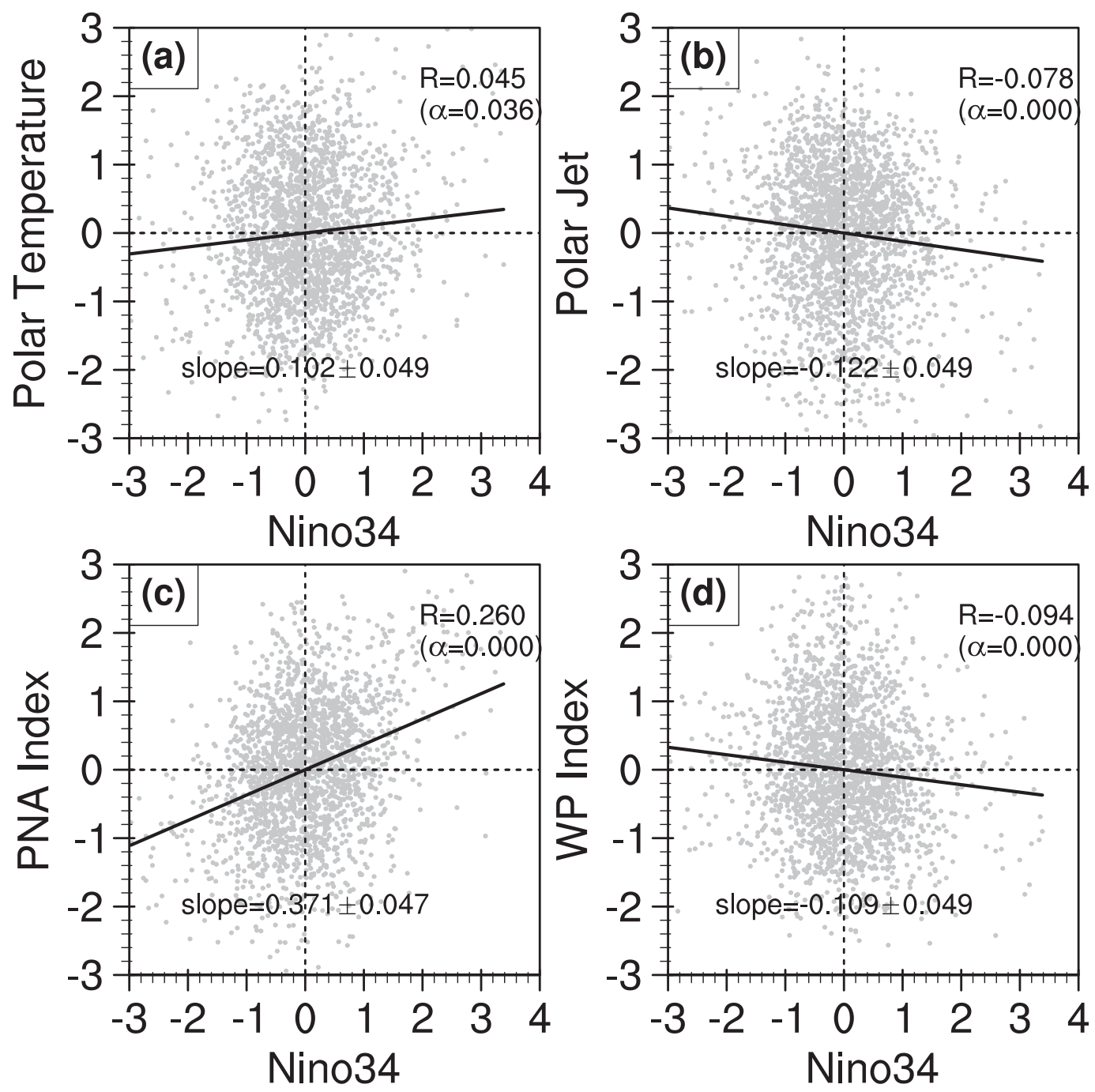

FIG. 2. As in Fig. 1, but the winter Niño-3.4 index and the four circulation indices are extracted from the CMIP5 MME.

shows a positive slope, and the slope is significantly different from zero at the $98 \%$ confidence level $(\alpha=$ 0.012 ) by a Student's $t$ test. The stratospheric circumpolar westerly jet is negatively correlated with the ENSO index at the $85 \%$ confidence level $(\alpha=0.142$; Fig. 1b). Note that the $U_{\text {pole }}$ points are scattered about the linear best fit due to the large chaotic noise in the stratosphere. The tropospheric ENSO teleconnections, including the PNA and WP, can enhance the extratropical planetary waves to disturb the stratospheric polar vortex (Garfinkel and Hartmann 2008; Fletcher and Kushner 2011; Rao and Ren 2018). Most points for PNA are mainly scattered above the zero line in El Niño winters and below it in La Niña winters (Fig. 1c). The WP mainly exhibits a seesaw pressure pattern between the Aleutian low and the subtropical high (Wallace and
Gutzler 1981), which mainly modulates the extratropical wavenumber-2 response, interfering with its climatology (Hu et al. 2017). The positive WP tends to coincide with La Niña (Fig. 1d) and corresponds to a weakened Aleutian low and inhibits the upward propagation of planetary waves.

The simulated relationships between the Niño-3.4 index and the $T_{\text {pole }}, U_{\text {pole }}$, PNA, and WP from the CMIP5 MME are shown in Figs. 2a-d, respectively. The correlation between ENSO and each of the four indicators is smaller than in the observations with the sample sizes increasing to more than 2100 . The slope of the fitting equation between Niño-3.4 and each of the four indicators is different among the 14 CMIP5 models. The slope in some models is larger than the CMIP5 MME, but still smaller than the observations (not 
shown). Despite the deficiency, the significant negative relationship between ENSO and the intensity of the northern winter stratospheric polar vortex is successfully reproduced by the CMIP5 MME (Figs. 2a,b). The strengthened Aleutian low during El Niño winters is also successfully simulated in models, and this Aleutian low response projects onto the positive PNA phase and negative WP phase (Figs. 2c,d). All of the four indicators are fairly scattered for every Niño-3.4 value from -3 to $4 \mathrm{~K}$, due to large internal variability in the troposphere and stratosphere. We also assessed sensitivity to changing the ENSO index from Niño-3.4 to Niño-3 or Niño-4 and then reinvestigating the relationship between ENSO and each indicator in the CMIP5 MME, but the main conclusions are nearly unchanged.

\section{ENSO SST patterns during the positive and negative PDO in the CMIP5 MME}

The SST anomalies from the 14 CMIP5 models are concatenated in a fixed order to construct the 2164-yr data, which are used to calculate the PDO for the CMIP5 MME. Figure 3 shows the regressed PDO SST patterns and the spectrum analysis for the normalized PDO time series from HadISST and the concatenated CMIP5 MME, respectively. It can be seen that anomalous cool water forms in the central North Pacific region and warm water dominates in the western coast of North America and the tropical-subtropical Pacific regions during the positive PDO (Figs. 3a,b). The simulated PDO is largely consistent with the horseshoe-shaped pattern of the North Pacific SST anomalies from the observations. However, the cold anomaly center in the central North Pacific from HadISST is biased farther westward and maximized near Japan in the MME. The warm SST anomaly magnitude near the Gulf of Alaska is overestimated in the MME. Those biases in the MME are also present in CESM1-WACCM (Fig. 2 in Kren et al. 2016). The SST total variance explained by the PDO mode in the extratropical Pacific is similar between the CMIP5 MME and the observations (25\% vs $23 \%$ ). The most significant period for the PDO index in HadISST is between 50 and 120 months (Fig. 3c), which is also reproduced in the CMIP5 MME (Fig. 3d). Generally, the spectrum peak around the decadal period for the PDO index is well simulated in models.

With the 2164-yr model data, a large number of ENSO events can be picked out for our composite study. The numbers of the four different configurations between ENSO and PDO from the CMIP5 MME are shown in Table 2. We will use "El/P", "El/N", "La/P", and "La/N" to denote the El Niño/positive PDO, El Niño/negative PDO, La Niña/positive PDO, and La Niña/negative PDO configurations, respectively. We find that during the positive PDO phase, El Niño events are nearly twice as likely to happen as La Niña events. In contrast, La Niñas occur more frequently than El Niños in the negative PDO phase. The composite El Niño intensity is nearly $1 \mathrm{~K}$ over the Niño-3.4 region in the CMIP5 MME, and the composite La Niña intensity is around $-1.0 \mathrm{~K}$.

The composite northern winter (December-February) SST anomaly patterns for the four ENSO/PDO configurations from the CMIP5 MME are shown in Fig. 4. The PDO can modulate the distribution of the El Niñorelated SST anomalies, especially in the North Pacific. Compared to negative PDO phases (Fig. 4b), positive PDO phases (Fig. 4a) enhance cold SST anomalies in the central North Pacific. The North Pacific cold SST anomalies fail to form in the $\mathrm{El} / \mathrm{N}$ winters, which are overwhelmed by the local warm SST anomalies related to the negative PDO. The SST anomalies in tropics during El Niño winters show little difference during the positive and negative PDO phases (Fig. 4c). Note that the tropical El Niño warm SST anomalies are filtered out in Fig. 4c, because the SST difference between El/P and El/N shows a PDO SST pattern focused in the extratropics. Therefore, the different atmospheric responses in $\mathrm{El} / \mathrm{P}$ and $\mathrm{El} / \mathrm{N}$ winters (see section 5) can be mainly attributed to the different SST anomalies in the North Pacific (Fig. 4c). Similarly, the tropical La Niña cold SST anomalies also show little difference between the positive and negative PDO phases (Figs. 4d-f). The La Niña-related warm SST anomalies in the central North Pacific during negative PDO phases (Fig. 4e) change to cold SST anomalies during positive PDO phases (Fig. 4d). The different atmospheric responses in La/P and $\mathrm{La} / \mathrm{N}$ winters are assumed to be due to the PDO SST forcing in the North Pacific (Fig. 4f).

Comparing the El Niño and La Niña SST patterns, cold SST anomalies dominate in the central North Pacific during positive PDO phases, whereas the tropical SST anomalies are oppositely signed with similar amplitudes (Figs. 4a,d). The amplitudes of El Niño and La Niña events in the tropics are also similar during negative PDO phases (Figs. 4b,e). Therefore, the sum of El Niño and La Niña SST anomalies in the tropics is nearly zero; the residual is the positive or negative PDO in the North Pacific (Figs. 4g,h). The observed asymmetric intensities of El Niño and La Niña are not present in the MME: only super El Niño events have been observed (Rao and Ren 2017; Garfinkel et al. 2018; Rao et al. 2019; Zhao et al. 2019), whereas both super El Niño and La Niña events are simulated in the MME (Tweedy et al. 2018). It is also noticed that the SST anomaly patterns in the El/P and $\mathrm{La} / \mathrm{N}$ winters are highly symmetric (Figs. 4a,e), which can be verified by their small sum (Fig. 4i). 

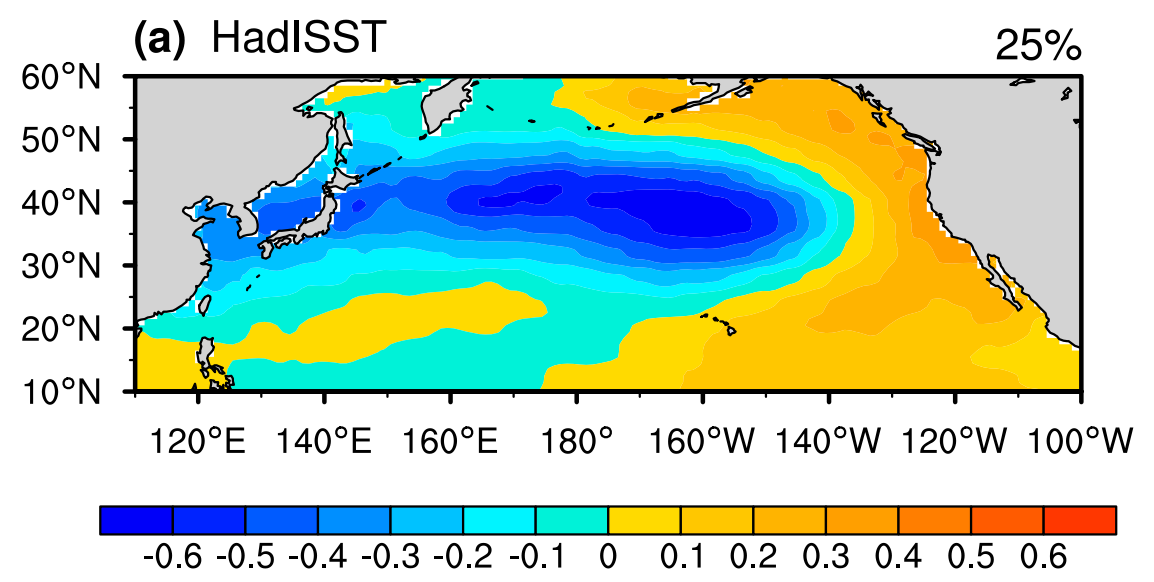

(b) MME
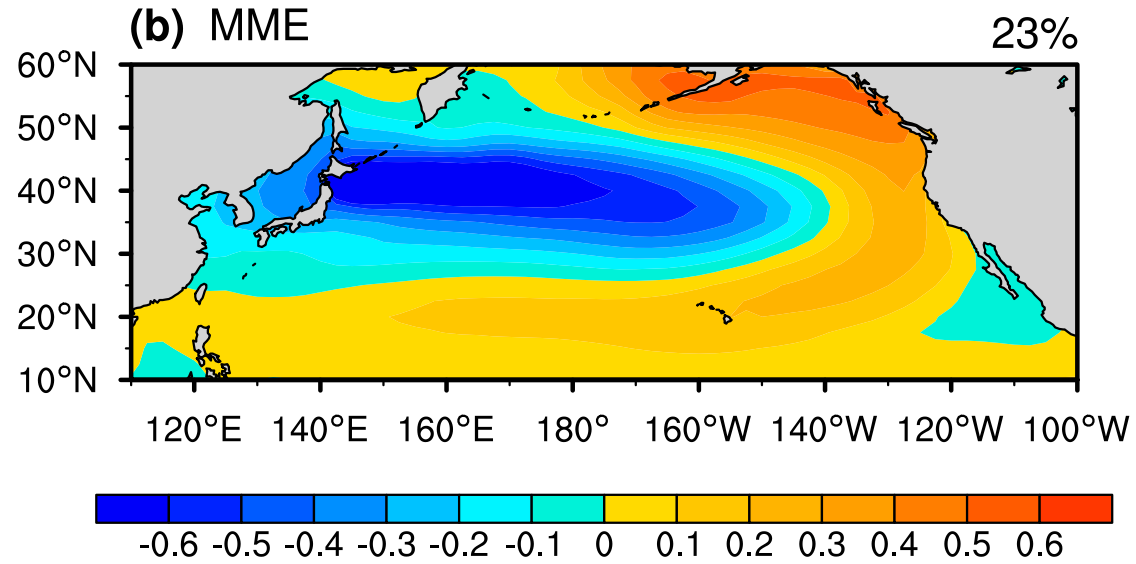

(c) HadISST

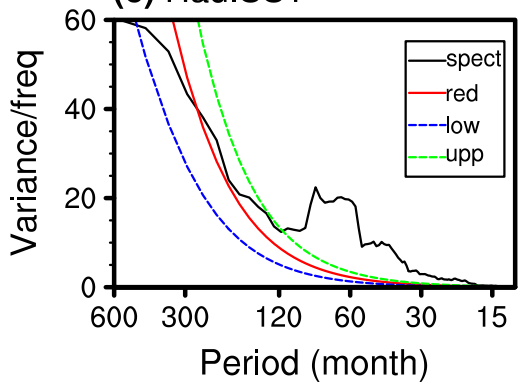

(d) MME

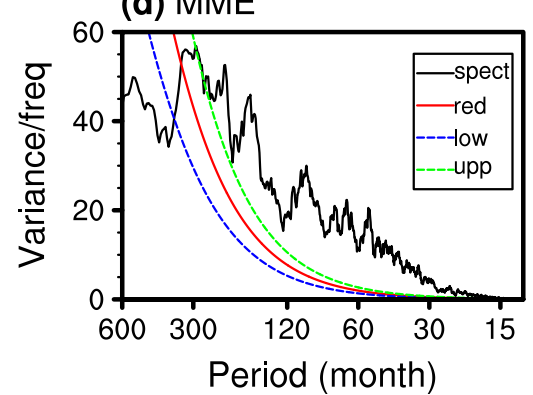

FIG. 3. Regressed SST anomalies (K) against the normalized PDO index defined as the first EOF time series of the Pacific SST anomalies poleward of $20^{\circ} \mathrm{N}$ in (a) HadISST and (b) the CMIP5 MME. (c),(d) The spectrum analysis for the monthly PDO index from HadISST and the CMIP5 MME (black: spectrum; red: red noise; green: upper confidence bound; blue: lower confidence bound), respectively.

\section{Modulation of the ENSO teleconnection by the PDO in the CMIP5 MME}

\section{a. The PDO modulates zonal-mean temperature response to ENSO}

The pressure-latitude distributions of the winter mean (December-February) zonal-mean temperature responses to ENSO and their modulation by the PDO are shown in Fig. 5. The tropical temperature responses to El Niño events show little difference during the positive and negative PDO with warm anomalies in the troposphere and cold anomalies in the stratosphere (Figs. 5a,b). However, the extratropical temperature responses to El Niño events during the positive and 
TABLE 2. The ENSO event numbers classified by the PDO phases in the 2164-yr total run by the CMIP5 MME. The number in parentheses in the second column is the composite Niño-3.4 index (K). P and $\mathrm{N}$ indicate the positive and negative phases of the PDO, respectively; $\mathrm{El}$ and La indicate El Niño and La Niña events, respectively.

\begin{tabular}{cl}
\hline \hline $\begin{array}{c}\text { ENSO/PDO } \\
\text { configuration }\end{array}$ & CMIP5 MME \\
\hline $\mathrm{El} / \mathrm{P}$ & $361(1.10 \mathrm{~K})$ \\
$\mathrm{El} / \mathrm{N}$ & $191(0.97 \mathrm{~K})$ \\
$\mathrm{La} / \mathrm{P}$ & $204(-0.96 \mathrm{~K})$ \\
$\mathrm{La} / \mathrm{N}$ & $353(-1.03 \mathrm{~K})$ \\
\hline
\end{tabular}

negative PDO are different. Anomalously warm and weak stratospheric polar vortices appear in $\mathrm{El} / \mathrm{P}$ winters, but no significant signal in the Arctic stratosphere is observed in $\mathrm{El} / \mathrm{N}$ winters. Thus a sample of $\mathrm{El}$ Niño events taken during alternate PDO phases should not be expected to have a similar stratospheric response. After the tropical El Niño SST anomalies are filtered out by the difference between Figs. 5a and 5b, the effect of the North Pacific SST anomalies on the atmosphere can be obtained (Fig. 5c). The positive-minus-negative difference for the PDO in El Niño winters exhibits a weaker and warmer polar vortex in the stratosphere.
Similarly, the zonal-mean temperature responses to La Niña events show little difference in the tropics during the positive and negative PDO, because of the similar La Niña intensities (Figs. 5d,e). Nevertheless, the CMIP5 MME shows that the extratropical responses in $\mathrm{La} / \mathrm{P}$ and $\mathrm{La} / \mathrm{N}$ winters have different patterns. A significant warm response appears in the Arctic upper stratosphere in La/P winters, but a colder and stronger stratospheric polar vortex is formed in $\mathrm{La} / \mathrm{N}$ winters. The positive-minus-negative difference for the PDO in La Niña winters also reflects the impact of the positive PDO on the atmosphere (Fig. 5f), consistent with Fig. 5c. The response patterns in El/P and $\mathrm{La} / \mathrm{N}$ winter are generally symmetric (Figs. $5 \mathrm{a}$,e), and the zonal-mean response in El/ $\mathrm{N}$ winters seems to be the mirror image of the response in $\mathrm{La} / \mathrm{P}$ winters (Figs. 5b,d). In conclusion, the positive PDO can enhance the stratospheric response to El Niño but destructively interfere with the extratropical response to La Niña, whereas the negative PDO can enhance the stratospheric response to La Niña but cancel out the stratospheric response to El Niño.

\section{b. Sensitivity of tropospheric ENSO teleconnections to the PDO phase}

Figure 6 shows the composite precipitation and 200$\mathrm{hPa}$ geopotential height responses to ENSO with the
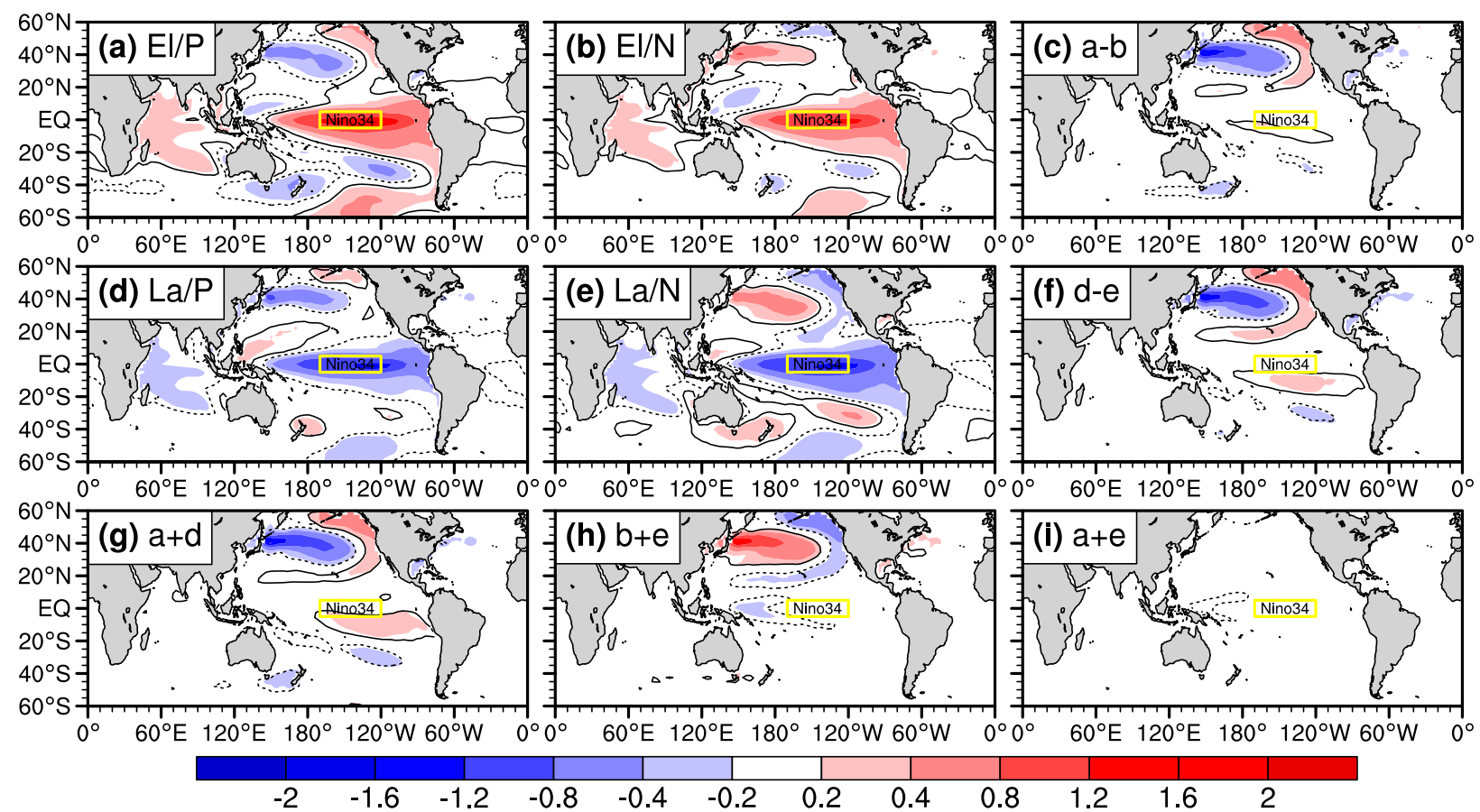

FIG. 4. Composite SST anomalies (shading; K) during (a),(b) El Niño and (d),(e) La Niña winters when the PDO is in its positive phase in (a) and (d) and negative phase in (b) and (e). (c),(f) The differences of El Niño/La Niña SST anomalies between positive and negative phases of the PDO, which correspond to the PDO SST anomaly pattern. (g),(h) The sum of El Niño and La El Niña during the positive and negative phases of the PDO. (i) The sum of (a) and (e). The black contours mark the SST anomalies at the $95 \%$ confidence level according to the Student's $t$ test. 

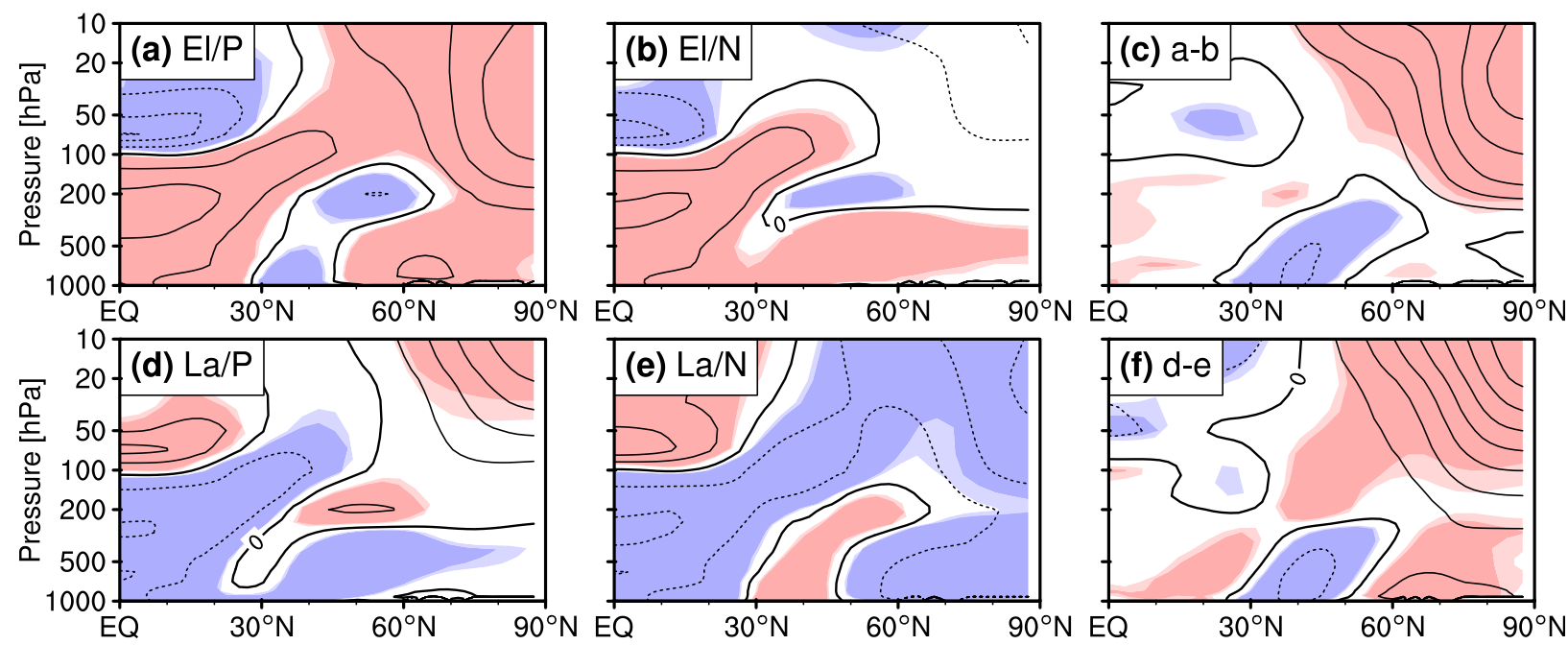

FIG. 5. Pressure-latitude cross sections of composite zonal-mean temperature anomalies (contours; K; interval: 0.25) during (a),(b) El Niño and (d),(e) La Niña winters when the PDO is in its (left) positive and (center) negative phases. (c),(f) The differences of composite zonal-mean temperature anomalies between positive and negative phases of the PDO, which correspond to the PDO modulations on the ENSO teleconnection. The light and dark shadings mark the temperature anomalies at the $90 \%$ and $95 \%$ confidence levels according to the Student's $t$ test, respectively.

PDO modulations from the CMIP5 MME. El Niño warm SST anomalies in the middle and eastern tropical Pacific enhance convection and lead to more rainfall (Figs. 6a,b). As the composite ENSO intensity shows little difference between $\mathrm{El} / \mathrm{P}$ and $\mathrm{El} / \mathrm{N}$ winters, the tropical precipitation and height responses are also similar. In the extratropics, however, the PNA response is stronger in El/P winters than in $\mathrm{El} / \mathrm{N}$ winters, and the anomalous Aleutian low is much stronger in Fig. 6a than in Fig. 6b. The different extratropical height anomalies over the North Pacific are mainly modulated by the local SST anomalies associated with the PDO (Fig. 6c).

Similarly, the negative PNA response and its positive height lobe over the North Pacific only appear in La/N winters, and no significant height anomalies form over the North Pacific in La/P winters (Figs. 6d,e). The different height anomalies over the North Pacific between $\mathrm{La} / \mathrm{P}$ and $\mathrm{La} / \mathrm{N}$ winters are also mainly caused by the local PDO SST anomalies. An anomalous low, albeit nonsignificant, appears in the North Pacific in La/P winters (Fig. 6d), which is mainly forced by the North
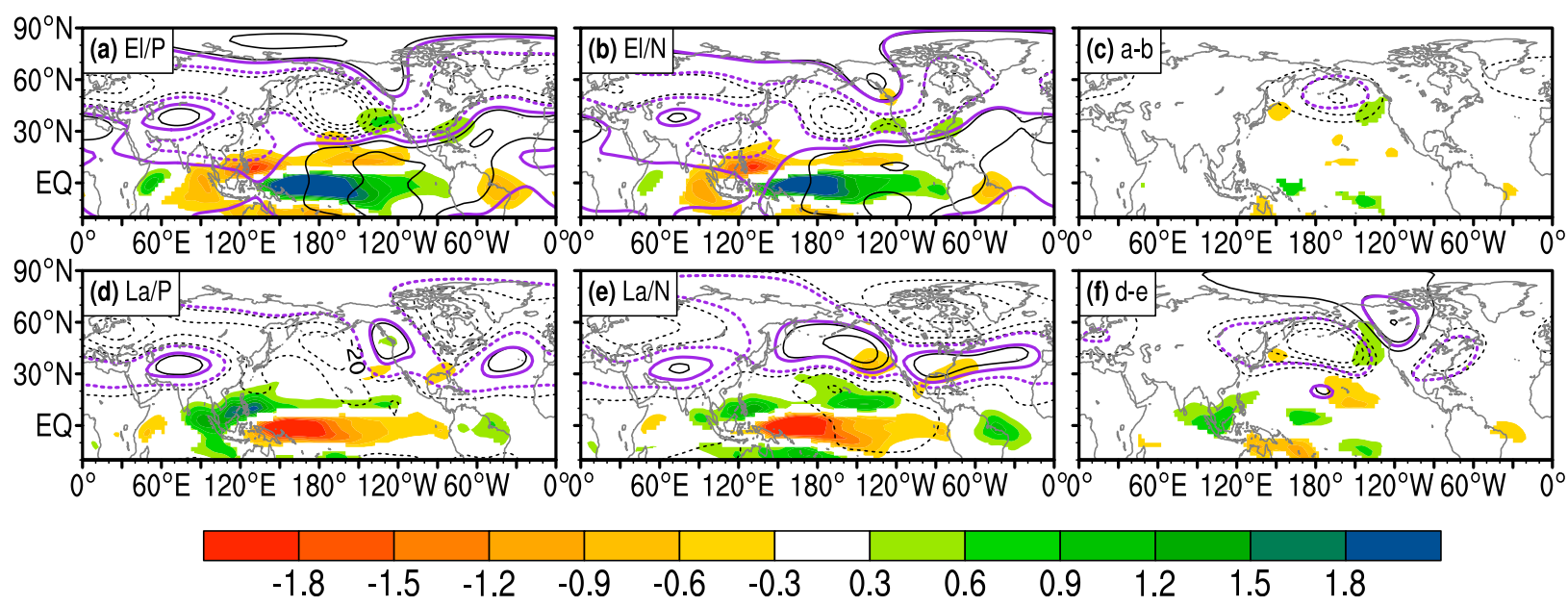

FIG. 6. Composite precipitation anomalies (shading; $\mathrm{mmm}_{\text {day }}{ }^{-1}$ ) and 200-hPa height anomalies (contours; gpm; interval: 10) during (a),(b) El Niño and (d),(e) La Niña winters when the PDO is in its (left) positive and (center) negative phases. (c),(f) The differences of composite precipitation and 200-hPa height anomalies between positive and negative phases of the PDO. Only precipitation anomalies at the $95 \%$ confidence level are shown. Purple contours mark the height anomalies at 95\% confidence level according to the Student's $t$ test. 

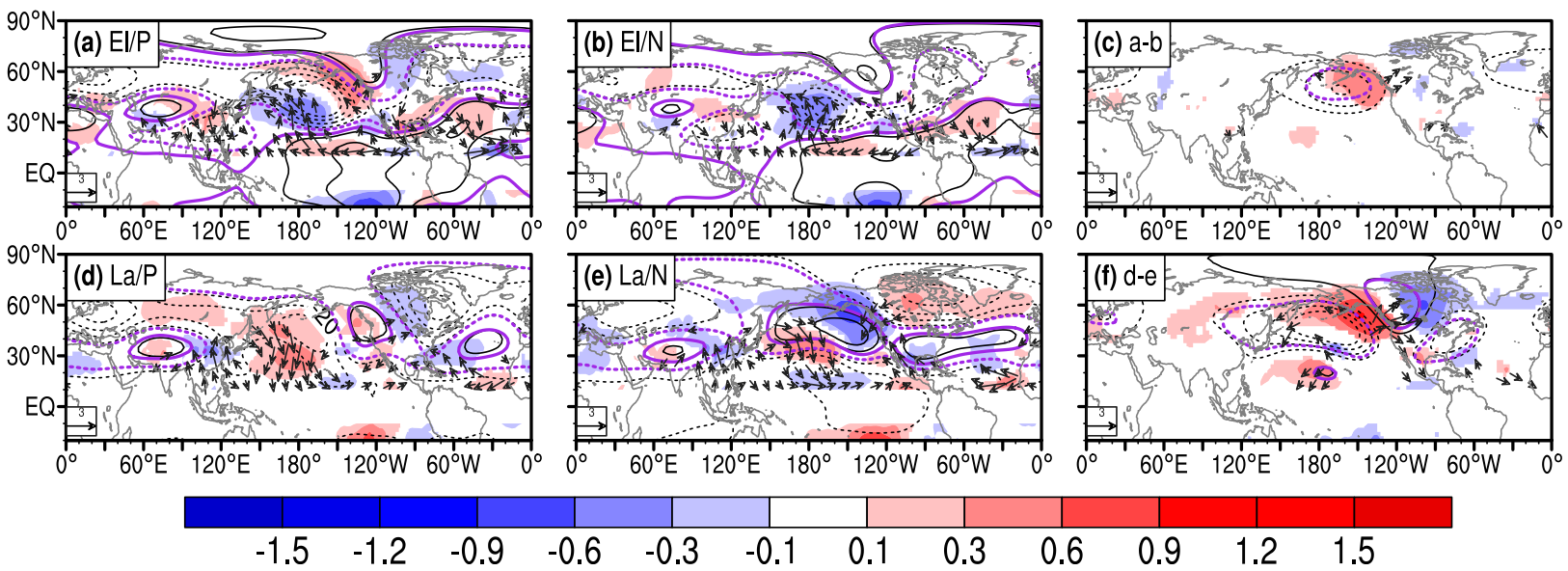

FIG. 7. Composite 200-hPa height anomalies (contours; gpm; interval: 10) and 200-hPa wave activity flux anomalies (vectors for the horizontal component, $\mathrm{m}^{2} \mathrm{~s}^{-2}$; shading for the vertical component, $10^{-2} \mathrm{~m}^{2} \mathrm{~s}^{-2}$ ) during (a),(b) El Niño and (d),(e) La Niña winters when the PDO is in its (left) positive and (center) negative phases. (c),(f) The differences of composite 200-hPa height and wave activity flux anomalies between positive and negative phases of the PDO. Only wave activity flux anomalies at the $95 \%$ confidence level are shown. Purple contours mark the height anomalies at 95\% confidence level according to the Student's $t$ test.

Pacific cold SST anomalies. The La Niña teleconnection during the negative PDO is mostly symmetric to the El Niño teleconnection during the positive PDO, especially in the Pacific sector (Figs. 6a,e). After the tropical La Niña SST forcing is filtered out, the atmospheric response to the positive PDO in Fig. 6f resembles a positive PNA-like pattern (e.g., Hurwitz et al. 2012; Mills and Walsh 2013; Woo et al. 2015; Kren et al. 2016). Therefore, the North Pacific SSTs associated with the PDO and the tropical Pacific ENSO SSTs are equally important for the excitation of the PNA. When the PDO and ENSO are in phase, the strong PNA response appears in the extratropics, whereas when the PDO and ENSO are out of phase the extratropical response to ENSO is destructed and even cancelled by the North Pacific SST forcing.

To investigate the relationship between the PNA response and the upward propagation of Rossby waves, the composite 200-hPa wave activity flux (Plumb 1985) and height responses in different ENSO winters are shown in Fig. 7. The PNA response over the extratropical Pacific is intimately related to the excited wave train emanating from the tropical Pacific caused by the enhanced convection associated with El Niño SST anomalies (Figs. 7a,b). Large wave activities mainly begin from the subtropical central Pacific and propagate across the North Pacific and North America. The horizontal wave activity flux over the North Pacific is similar between $\mathrm{El} / \mathrm{P}$ and $\mathrm{El} / \mathrm{N}$ winters. However, the vertical propagation of planetary waves is different between the positive and negative PDO. The upward propagation of Rossby waves is mainly located over East Asia and the western coast of North America in the positive PDO, while this vertical propagation disappears in the negative PDO. The atmospheric response to the "pure" positive PDO exhibits a deepened Aleutian low and the enhanced upward propagation of waves along the western coast of North America (Fig. 7c).

In contrast, the $200-\mathrm{hPa}$ wave flux response in $\mathrm{La} / \mathrm{P}$ winters is mainly determined by the North Pacific cold SST anomalies (Fig. 7d). The anomalous waves propagate upward in the East Asia and the western coastal Canada but propagate downward in the Northern Hemisphere midlatitudes of the Atlantic sector. Positive height anomalies are present in the North Pacific sector in $\mathrm{La} / \mathrm{N}$ winters collocated with the climatological stationary trough, implying the weakening of the extratropical climatological waves; meanwhile, the upward propagation of waves over the western coast of North America and East Asia is reduced (Fig. 7e). A positiveminus-negative difference for the PDO during La Niña winters also exhibits a positive PNA-like response and an increase in the upward-propagating waves along the western coast of North America (Fig. 7f), consistent with Fig. 7c. The upward-propagating waves and PNA pattern in Fig. $7 \mathrm{f}$ are stronger than in Fig. 7c, because the PDO SST anomalies especially in the tropical Pacific are larger for Fig. 7f (cf. Fig. 4f) than for Fig. 7c (cf. Fig. 4c).

The anomalous upward-propagating waves can interfere with the climatological troughs and ridges to disturb the stratospheric polar vortex (Manzini et al. 2006; Camp and Tung 2007; Garfinkel and Hartmann 2008, Ineson and Scaife 2009; Garfinkel et al. 2010; Fletcher and Kushner 2011; Ren et al. 2017). To better 

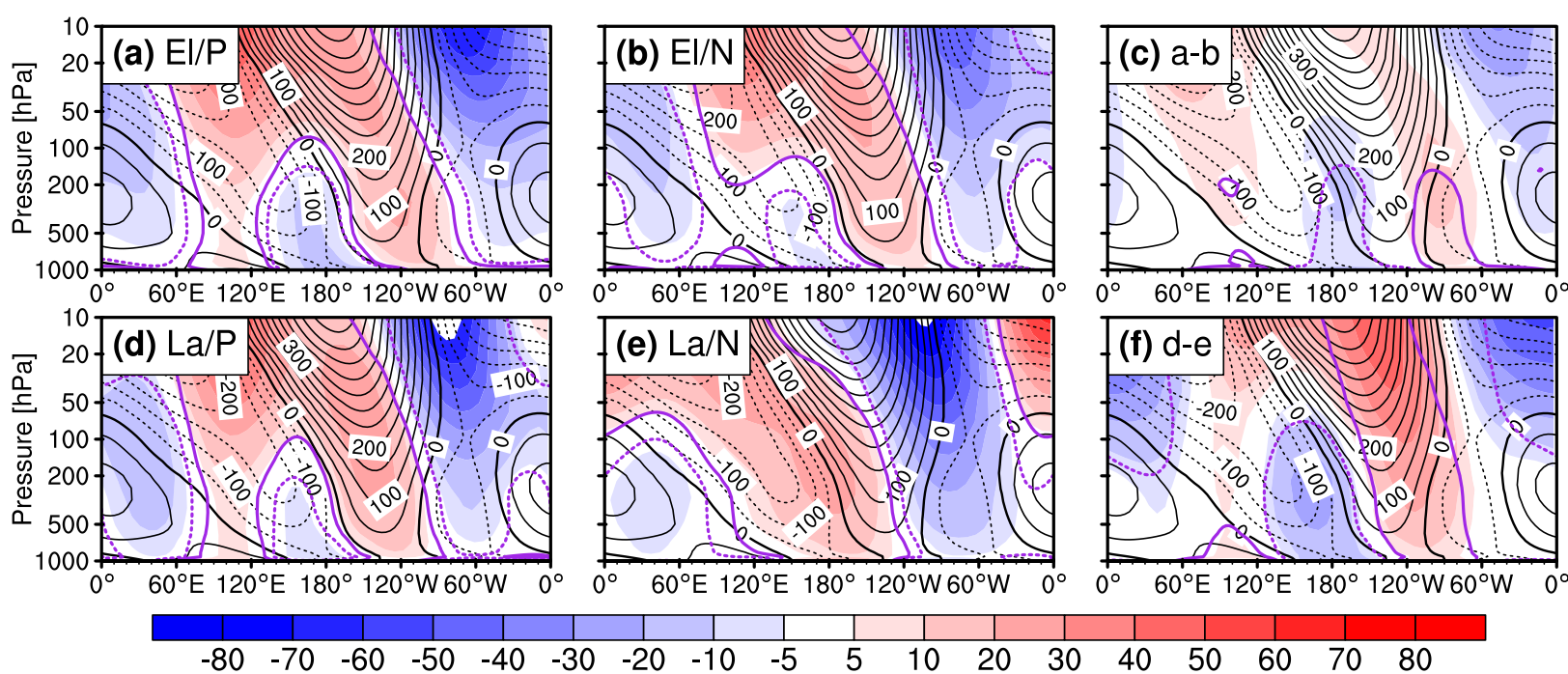

FIG. 8. Pressure-longitude cross sections of composite eddy height anomalies averaged in the $45^{\circ}-75^{\circ} \mathrm{N}$ latitude band (shading; gpm) during (a),(b) El Niño and (d),(e) La Niña winters when the PDO is in its (left) positive and (center) negative phases. (c),(f) The differences of composite eddy height anomalies between positive and negative phases of the PDO. Contours are the corresponding eddy height climatology (gpm) in the $45^{\circ}-75^{\circ} \mathrm{N}$ latitude band. Purple contours mark the eddy height anomalies at $95 \%$ confidence level according to the Student's $t$ test.

understand the interference of the extratropical height response within the climatological planetary waves, the pressure-longitude distribution of the eddy height responses averaged in the circumpolar region $\left(45^{\circ}-75^{\circ} \mathrm{N}\right)$ is shown in Fig. 8 for the four configurations of ENSO and PDO. The negative tropospheric height response centered near the date line is obviously stronger in El/P winters than in $\mathrm{El} / \mathrm{N}$ winters (Figs. 8a,b), consistent with Figs. $6 \mathrm{a}, 6 \mathrm{~b}, 7 \mathrm{a}$, and $7 \mathrm{~b}$. As a result, the eddy height response is also stronger in $\mathrm{El} / \mathrm{P}$ winters than in $\mathrm{El} / \mathrm{N}$ winters, which is nearly in phase with the climatological eddy height (contours) and enhances the total waves. The eddy height response exhibits a westward tilt, favoring upward propagation of planetary waves. The difference between $\mathrm{El} / \mathrm{P}$ and $\mathrm{El} / \mathrm{N}$ indicates that the positive PDO causes negative height anomalies over the central North Pacific and positive height anomalies over North America (Fig. 8c). The extratropical eddy height response in $\mathrm{La} / \mathrm{P}$ winters is mainly determined by the North Pacific SST anomalies, whereas the eddy height response is nearly out of phase with its climatology in $\mathrm{La} / \mathrm{N}$ winters (Figs. 8d,e). The PDO modulates the extratropical wave response to ENSO (Fig. 8f) and explains the unstable extratropical response to La Niña.

\section{c. Upward propagation of planetary waves and stratospheric response}

Figure 9 presents the composite Eliassen-Palm (E-P) flux anomalies (Andrews et al. 1987) in the CMIP5 MME to demonstrate changes in the upward propagation of planetary waves from the troposphere to stratosphere. As the positive PNA response appears in El/P winters, the upward propagation and dissipation of planetary waves are indeed intensified in mid-to-high latitudes (Fig. 9a). The climatological upward propagation of waves in midto-high latitudes is somewhat inhibited in $\mathrm{El} / \mathrm{N}$ winters, which is mainly caused by the central North Pacific warm SST anomalies (Fig. 9b). As a result, the polar jet is decelerated in $\mathrm{El} / \mathrm{P}$ winters while it is less disturbed in $\mathrm{El} / \mathrm{N}$ winters. Similarly, the suppressed upward propagation of planetary waves in the circumpolar region is found in $\mathrm{La} /$ $\mathrm{N}$ winters with the polar jet acceleration (Fig. 9e), whereas a weaker polar jet response is observed in $\mathrm{La} / \mathrm{P}$ winters, due to the increase in upward propagation of waves into the Arctic stratosphere (Fig. 9d). The modulation of the PDO for E-P flux and zonal-mean zonal winds is consistent in $\mathrm{El}$ Niño and La Niña winters (Figs. 9c,f). The composite differences between El Niño and La Niña are fairly similar during the positive and negative phases of the PDO (Figs. 9g,h), and the E-P flux differences between $\mathrm{El} / \mathrm{P}$ and $\mathrm{La} / \mathrm{N}$ winters are stronger in Fig. 9i than in Figs. 9g and 9h. The high similarity between Figs. $9 \mathrm{~g}$ and $9 \mathrm{~h}$ implies that the PDO might not explain the observed nonstationarity of the stratospheric ENSO teleconnection in recent decades (Hu et al. 2017; Yang et al. 2017; Domeisen et al. 2019; also see the review in section 1 herein).

The composite height zonal wavenumber-1 response at $10 \mathrm{hPa}$ is shown in Fig. 10 to compare the stratospheric disturbances as a result of anomalous upward 

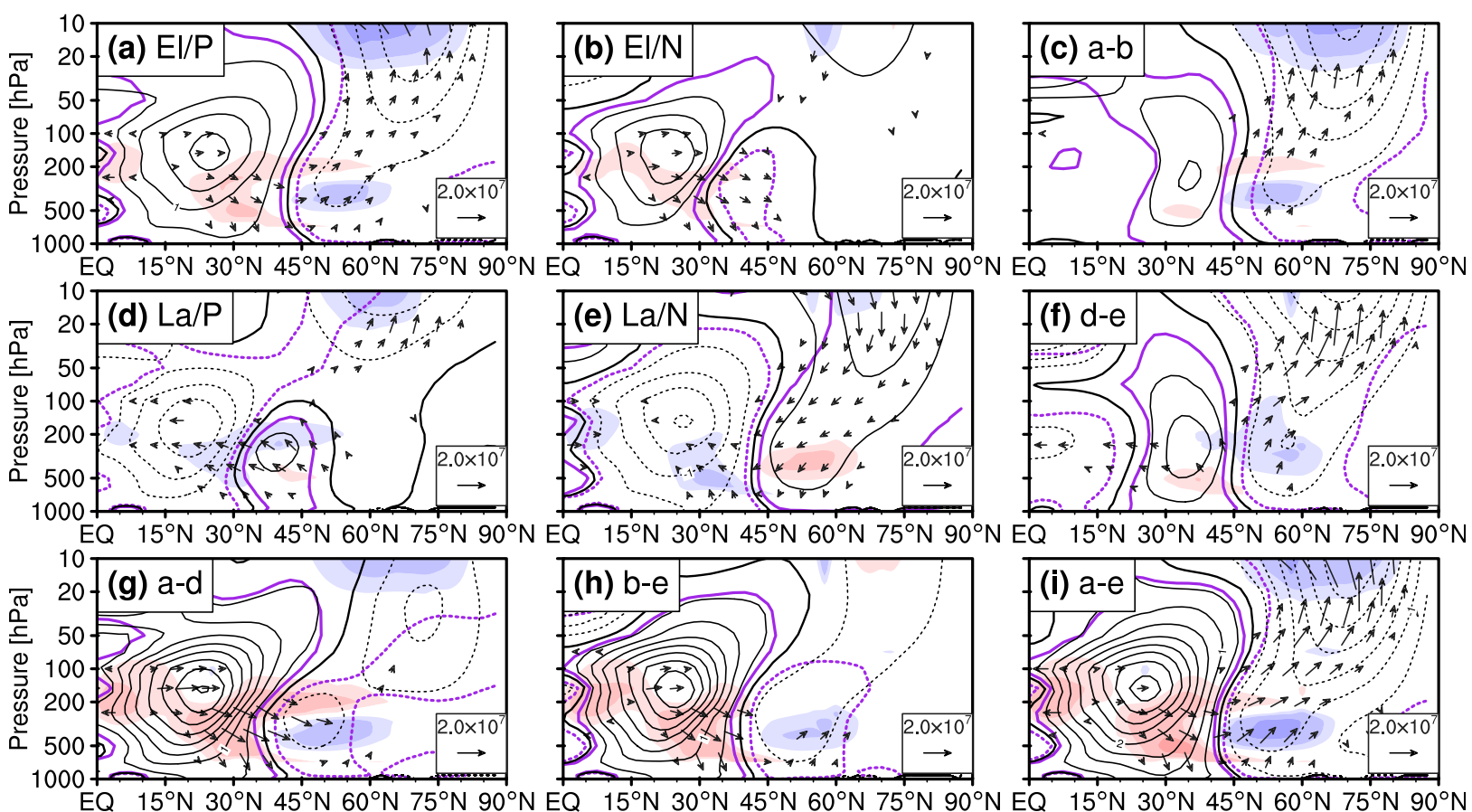

EQ $15^{\circ} \mathrm{N} 30^{\circ} \mathrm{N} 45^{\circ} \mathrm{N} 60^{\circ} \mathrm{N} 75^{\circ} \mathrm{N} 90^{\circ} \mathrm{N}$
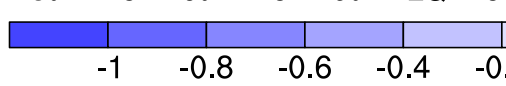

FIG. 9. Pressure-latitude cross sections of composite zonal-mean zonal wind anomalies (contours; $\mathrm{m} \mathrm{s}^{-1}$; interval: 0.5 ), composite E-P flux anomalies (vectors; $\mathrm{m}^{3} \mathrm{~s}^{-2}$; normalized by local air density for clarity), and composite E-P flux divergence anomalies (shading; $\mathrm{m} \mathrm{s}^{-1}$ day $^{-1}$ ) during (a),(b) El Niño and (d), (e) La Niña winters when the PDO is in its positive phase in (a) and (d) and negative phase in (b) and (e). (c),(f) The differences of composite zonal-mean zonal wind, E-P flux, and E-P flux divergence between positive and negative phases of the PDO. (g)-(i) As in (c),(f), but for the differences between El Niño and La Niña. Only E-P flux anomalies and E-P flux divergence anomalies at the $95 \%$ confidence level are shown. Purple contours mark the zonal wind anomalies at $95 \%$ confidence level according to the Student's $t$ test.

propagation of waves from the troposphere. The wavenumber- 1 response amplitude at $10 \mathrm{hPa}$ is stronger in $\mathrm{El} / \mathrm{P}$ winters than in $\mathrm{El} / \mathrm{N}$ winters, and the wavenumber-1 response to El Niño is nearly in quadrature with the wavenumber-1 climatology (Figs. 10a,b). The positive height anomalies centered over the North Eurasian continent enhance the climatological ridge, squeezing the polar vortex toward the North Atlantic. The wavenumber-1 response contributed by the positive PDO is nearly in phase with (but lags) the climatology and favors the displacement of the stratospheric polar vortex toward the Atlantic sector where the negative lobe of the wavenumber-1 prevails (Fig. 10c). The stratospheric wavenumber-1 responses in $\mathrm{La} / \mathrm{P}$ winters is determined by the North Pacific cold SST anomalies (cf. Figs. 10d,f). In contrast, the wavenumber- 1 response in $\mathrm{La} / \mathrm{N}$ winters is out of phase with its climatology (Figs. 10e). It is shown again that the PDO can interfere with ENSO to modulate the stratospheric wave response (Fig. 10f). It is also shown once again that the spatial pattern of the extratropical response difference between El Niño and La Niña (i.e., the pure "ENSO" teleconnection, with the PDO filtered out) is similar during the positive PDO and during the negative PDO, although the response amplitude is different (Figs. 10g,h). Overall, the strongest response usually appears when ENSO and PDO are in phase (Figs. 10a,e,i).

\section{EP ENSO versus CP ENSO in the CMIP5 MME \\ a. Two flavors of ENSO SST pattern in the CMIP5 $M M E$}

Previous studies have argued that the PDO can modulate the occurrence ratio of $\mathrm{EP}$ and $\mathrm{CP} \mathrm{El}$ Niños, which might explain the nonstationarity of the ENSO teleconnection (Ayarzagüena et al. 2019; Domeisen et al. 2019). Table 3 shows the occurrence frequencies of the two flavors of ENSO. The occurrence ratio between EP Niños and CP El Niños is 1.64 in the positive PDO (224/137), while this ratio increases to 2.13 in the negative PDO (130/61). In contrast, the occurrence ratio between EP La Niñas and CP La Niñas is 1.83 in the positive PDO (132/72), and this ratio decreases to 1.47 in the negative 

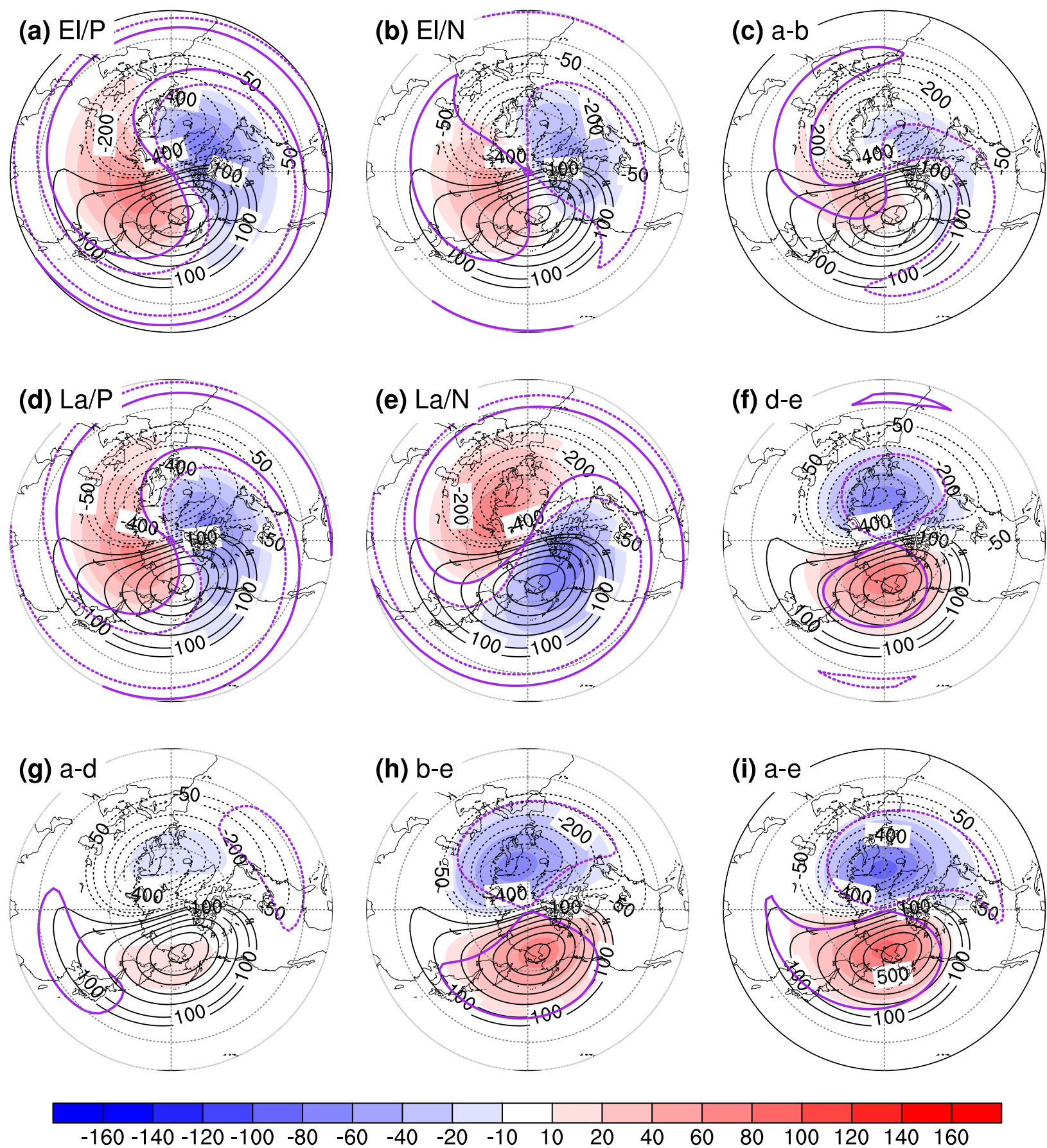

FIG. 10. Composite wavenumber-1 height anomalies at $10 \mathrm{hPa}$ during (a),(b) El Niño and (d),(e) La Niña winters when the PDO is in its positive phase in (a) and (d) and negative phase in (b) and (e) (shading; gpm). (c),(f) The differences of composite wavenumber-1 height anomalies between positive and negative phases of the PDO. (g)-(i) As in (c),(f), but for the differences between El Niño and La Niña. Contours are the corresponding winter height climatology (gpm) at $10 \mathrm{hPa}$. Purple contours mark the wavenumber- 1 height anomalies at $95 \%$ confidence level according to the Student's $t$ test.

PDO (210/143). To put it another way, more EP ENSO events occur in CMIP5, regardless of the ENSO phase and the PDO phase. Furthermore, El Niño events occur more frequently during the positive PDO phase than during the negative PDO phase for both ENSO flavors (224/130 and 137/61). Similarly, La Niña events occur more frequently during the negative PDO phase than during the positive PDO phase for both flavors (210/132 
TABle 3. As in Table 2, but the ENSO types [eastern Pacific (EP) and central Pacific (CP)] are considered. The three numbers inside parentheses in the second column are the composite Niño3.4, Niño-3, and Niño-4 indices (K), respectively. The abbreviations are as in Table 2 .

\begin{tabular}{cc}
\hline \hline $\begin{array}{c}\mathrm{ENSO} / \mathrm{PDO} \\
\text { configuration }\end{array}$ & CMIP5 MME \\
\hline $\mathrm{EP} \mathrm{El} / \mathrm{P}$ & $224(1.20,1.22,0.77)$ \\
$\mathrm{CP} \mathrm{El} / \mathrm{P}$ & $137(0.95,0.72,0.94)$ \\
$\mathrm{EP} \mathrm{El} / \mathrm{N}$ & $130(1.02,1.06,0.64)$ \\
$\mathrm{CP} \mathrm{El} / \mathrm{N}$ & $61(0.88,0.67,0.85)$ \\
$\mathrm{EP} \mathrm{La} / \mathrm{P}$ & $132(-0.97,-0.97,-0.65)$ \\
$\mathrm{CP} \mathrm{La} / \mathrm{P}$ & $72(-0.95,-0.72,-0.96)$ \\
$\mathrm{EP} \mathrm{La} / \mathrm{N}$ & $210(-1.03,-1.03,-0.71)$ \\
$\mathrm{CP} \mathrm{La} / \mathrm{N}$ & $143(-1.04,-0.80,-1.05)$ \\
\hline
\end{tabular}

and 143/72). On average, EP El Niños are stronger than CP El Niños, regardless of the PDO phase $(1.20 / 0.95 \mathrm{~K}$ and 1.02/0.88 K). The two flavors of La Niña events are comparable in their maximum SST anomalies $(-0.97 /$
$-0.95 \mathrm{~K}$ and $-1.03 /-1.04 \mathrm{~K})$. Note that our composite sizes are significantly larger than those of Hurwitz et al. (2014) and Calvo et al. (2017), as we use data from before 1950 and include moderate ENSO events.

The composite winter mean ENSO SST anomalies are shown in Fig. 11 for EP and CP ENSO flavors during the positive and negative PDO phases, respectively. Consistent with Fig. 4, since the SST anomalies in the tropics are fairly similar during the positive and negative PDO for the two ENSO flavors, the ENSO SST forcing in the tropics can be subtracted to deduce the effect of the PDO on the atmosphere that is superposed with ENSO. For example, the SST difference in the extratropical Pacific between EP El Niño events during the positive PDO and during the negative PDO largely resembles the PDO pattern (Figs. 11a-c), and a weak but significant SST difference also appears in the tropical Pacific. The CP El Niño events also exhibit similar tropical SST patterns during the positive and negative PDO phases in
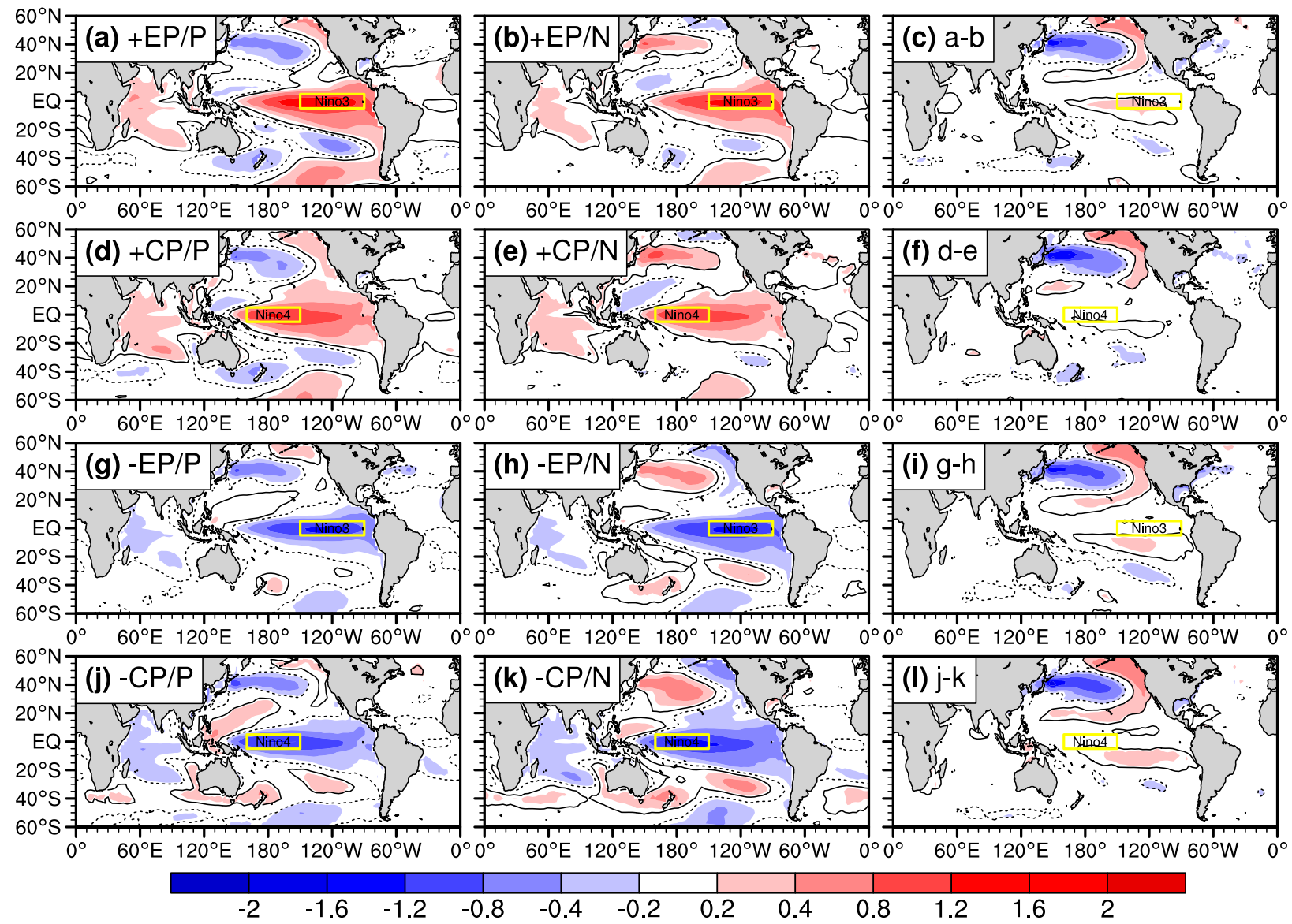

FIG. 11. Composite SST anomalies (shadings; K) during (a),(b) EP El Niño, (d),(e) CP El Niño, (g),(h) EP La Niña, and (j),(k) CP La Niña winters when the PDO is in its (left) positive and (center) negative phases. (c),(f),(i),(l) The differences of El Niño/La Niña SST anomalies between positive and negative phases of the PDO, which correspond to the PDO SST anomaly pattern. The black contours mark the SST anomalies at the $95 \%$ confidence level according to the Student's $t$ test. 

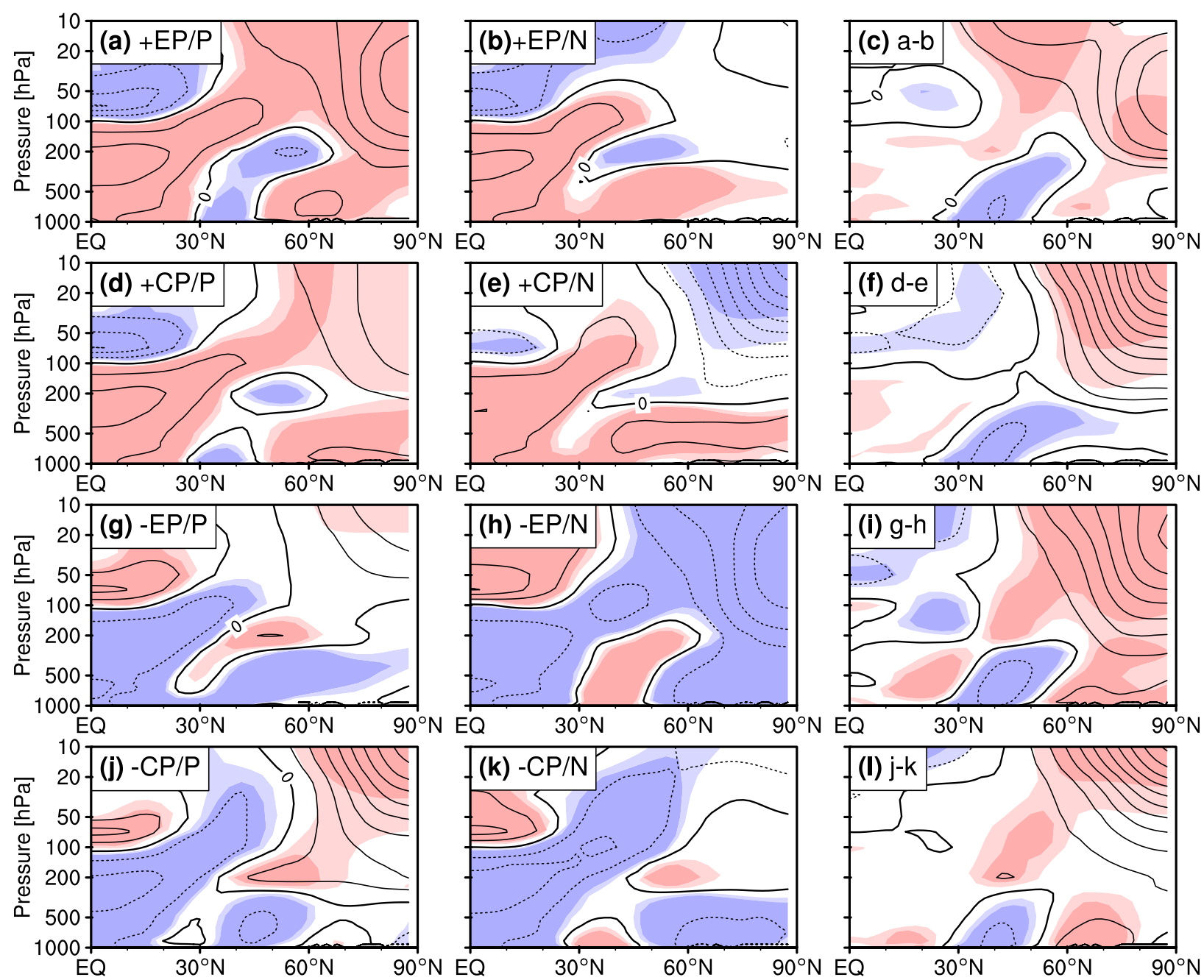

FIG. 12. Pressure-latitude cross sections of composite zonal-mean temperature anomalies (contours; K; interval: 0.25) during (a),(b) EP El Niño, (d),(e) CP El Niño, (g),(h) EP La Niña, and (j),(k) CP La Niña winters when the PDO is in its (left) positive and (center) negative phases. (c),(f),(i),(l) The differences of composite zonal-mean temperature anomalies between positive and negative phases of the PDO, which correspond to the PDO modulations on the ENSO teleconnection. The light and dark shadings mark the temperature anomalies at the $90 \%$ and $95 \%$ confidence levels according to the Student's $t$ test, respectively.

the CMIP5 MME (Figs. 11d,e). The largest SST difference between Figs. 11d and 11e is located in the North Pacific, explained by the PDO, and a much weaker SST difference forms in the tropical Pacific (Fig. 11f). The EP La Niña (Figs. 11g-i) and CP La Niña (Figs. 11j-1) related SST anomalies in the extratropical and tropical Pacific are also different between the positive and negative PDO phases. The CMIP5 MME also reveals that although the maximum SST anomalies for EP and CP in the tropical Pacific are located in different Niño regions, the central North Pacific is dominated by cold SST anomalies during the positive PDO (Figs. 11a,d,g,j) and by warm SST anomalies during the negative PDO (Figs. 11b,e,h,k). The symmetric component of the atmospheric responses to SST forcings in Figs. 11a, 11d,
$11 \mathrm{~g}$, and $11 \mathrm{j}$ is related to the positive PDO, as is also the case for Figs. 11b, 11e, 11h, and 11k.

\section{b. Zonal-mean temperature responses to two flavors of ENSO in CMIP5}

The pressure-latitude distributions of the zonalmean temperature responses to different ENSO flavors and the PDO interference are shown in Fig. 12. As EP ENSO events are much more frequent than CP ENSO events (Table 3), the zonal-mean temperature responses to ENSO in Fig. 3 are mainly dominated by EP ENSO. Specifically, the anomalously warm and weak stratospheric polar vortex only appears in EP El Niño winters during the positive PDO (Fig. 12a), and the anomalously cold and strong stratospheric polar 
vortex only appear in EP La Niña winters during the negative PDO (Fig. 12h). No significant signals are found when the EP ENSO and the PDO are out of phase (Figs. 12b,g). The tropical temperature responses are similar for EP and CP El Niños (Figs. 12a,b,d,e) as well as for EP and CP La Niñas (Figs. 12g,h,j,k), but the extratropical responses are different. The temperature anomaly sign in the Arctic stratosphere is mainly controlled by the PDO phase for CP ENSO. As in previous studies (Yu and Kim 2011; Graf and Zanchettin 2012; Garfinkel et al. 2013), the stratospheric warm response to CP El Niño events is weaker than that to EP El Niño events (Figs. 12a,d), but only during the positive PDO. Different from EP ENSO, the extratropical atmospheric responses are dominated by the PDO influence when the PDO and the CP ENSO are out of phase (Figs. 12e,j).

After tropical ENSO forcings subtracted for the same ENSO phase and flavor, the interferences of the PDO with El Niño and La Niña's impacts as well as with EP and CP ENSO's impacts are shown in Figs. 12c, 12f, 12i, and 121. The deduced PDO contribution from different ENSO phases and from different ENSO flavors are fairly similar, consistent with Figs. 5c and 5d, which implies that the PDO might mainly show a linear interference with the ENSO teleconnection in the extratropics. The dynamic diagnosis is similar to section 5 and is not shown here for succinctness.

\section{Summary and discussion}

\section{a. Summary}

Using the CMIP5 MME data with large sample size for ENSO, this study explores the possible modulation of the ENSO-northern winter stratosphere relationship by the PDO. The CMIP5 MME can reproduce the main tropospheric ENSO teleconnections such as the PNA and WP, as well as the stratospheric ENSO teleconnections. El Niño and La Niña events show large asymmetry in their occurrence during the two PDO phases. El Niños occur more frequently than La Niñas during the positive PDO in the CMIP5 MME, whereas more La Niñas appear than El Niños during the negative PDO.

The Arctic stratospheric responses are enhanced when the PDO and ENSO are in phase, warm in El/P winters and cold in $\mathrm{La} / \mathrm{N}$ winters. Because of the destructive interference of the PDO, the extratropical stratospheric response is fairly weak when the PDO and ENSO are out of phase. The positive PNA-like response and the negative height anomalies over the North Pacific are much stronger and more significant in $\mathrm{El} / \mathrm{P}$ winters than in $\mathrm{El} / \mathrm{N}$ winters. The North Pacific cold SST anomalies in El/P winters play a key role in enhancing the local height response over the North Pacific. The anomalous low and high responses in $\mathrm{El} / \mathrm{P}$ winters are collocated with the climatological trough and ridge, and thus the projected eddy height response is in phase with, and constructively interferes with, its climatology. The upward propagation of waves from the troposphere is enhanced over the western coast of North America and East Asia in $\mathrm{El} / \mathrm{P}$ winters. Conversely, the negative PNA response and the positive height anomalies over the North Pacific mainly appear in La/ $\mathrm{N}$ winters. The upward propagation of waves over the western coast of North America and East Asia is suppressed in La/N winters, which is nearly symmetric to the response in $\mathrm{El} / \mathrm{P}$ winters. When the PDO and ENSO are out of phase, the extratropical height response over the North Pacific is relatively weak and not significant, implying that the North Pacific SST forcing destructively interferes with the tropical ENSO forcing to influence the extratropical atmospheric response.

The extratropical eddy height response shows a westward tilt from the troposphere to the stratosphere and favors the upward propagation of anomalous planetary waves in El/P winters. The enhanced upwardpropagating waves dissipate in the mid-to-high-latitude stratosphere, weakening the stratospheric polar vortex. As the positive PNA response to $\mathrm{El}$ Niño is cancelled out by the warm PDO SST forcing in the central North Pacific, the upward propagation of the extratropical waves is not robustly changed in $\mathrm{El} / \mathrm{N}$ winters. A similar cancellation occurs during $\mathrm{La} / \mathrm{P}$ winters. In contrast, the climatological ridge and trough in the extratropics are weakened in La/N winters, and the upward propagation of waves is significantly inhibited in the mid-to-high latitudes, leading to a stronger polar vortex response.

The extratropical atmospheric response to the "pure" positive PDO also resembles a PNA-like response, deepening the climatological trough near the central North Pacific and enhancing the climatological ridge near western Canada; and vice versa for the negative PDO. The positive PDO strengthens the climatological wavenumber1 in the stratosphere, while the negative PDO weakens the climatological wavenumber-1. Therefore, when the PDO and ENSO are in phase, the upward propagation of waves in the mid-to-high latitudes is uniformly enhanced or weakened, and the polar vortex response is stronger. Nevertheless, when the PDO and ENSO are out of phase, the PDO destructively interferes with the ENSO forcing. However, the differences of the E-P flux and the stratospheric planetary waves between El Niño and La Niña are highly similar for the positive and negative phases of the PDO. Therefore, the PDO may not explain the nonstationarity of the ENSO-stratosphere relationship.

The interference of the PDO with the stratospheric temperature response is also discussed for different 
ENSO flavors. The occurrence ratio between EP El Niño and CP El Niño, as well as the ratio between EP La Niña and CP La Niña is much larger than 1.0 (1.5-2.0) in the MME, regardless of the PDO phase. In addition, El Niño occurs more frequently during the positive PDO than during the negative PDO, and La Niña occurs more frequently during the negative PDO than during the positive PDO, regardless of the ENSO flavors. Although the tropical maximum SST anomalies are located in different Niño regions for EP and CP ENSO, the North Pacific SST anomalies associated with the PDO can mingle with both ENSO flavors. In addition, the extratropical stratospheric responses exhibit different behaviors when the PDO and ENSO flavors are differently configured. The extratropical stratospheric responses are enhanced when the PDO and EP ENSO are in phase, whereas the extratropical stratospheric responses are intensified when the PDO and CP ENSO are out of phase with the response signs determined by the PDO phase.

\section{b. Discussion}

A seasonal cycle in the response of the stratosphere to the tropical SST anomaly forcing has also been noticed (Manzini et al. 2006; Garfinkel et al. 2013; King et al. 2018; Ayarzagüena et al. 2018; Jiménez-Esteve and Domeisen 2018; Rao and Ren 2018). Because of the annual cycle of the zonal mean flow and shift of the convection activities, the sources and propagation of planetary wave are different between early winter and late winter (Ayarzagüena et al. 2018). In contrast, the stratospheric response to ENSO in early winter (King et al. 2018) is weaker (November) than in the following months (Ayarzagüena et al. 2018; Jiménez-Esteve and Domeisen 2018; Rao and Ren 2018). This study mainly focuses on the strongest response in DecemberFebruary.

Since the reanalysis is short and sampling variability to an unknown extent may influence apparent connections between the Arctic stratosphere and decadal variability of the ocean (e.g., Garfinkel et al. 2018; Domeisen et al. 2019), this study uses the CMIP5 MME to explore the possible modulation of the ENSOstratosphere relationship by the PDO. The long outputs from the CMIP5 MME indicate an anomalously warm and weak stratospheric polar vortex response in $\mathrm{El} / \mathrm{P}$ winters and an anomalously cold and strong stratospheric polar vortex in $\mathrm{La} / \mathrm{N}$ winters. Model evidences reveal that the unstable relationship between El Niño (or La Niña) and the stratospheric circulation might be related to the local SST states in the North Pacific. However, the difference between El Niño and La Niña is similar regardless of the PDO phase, so the decadal change in the ENSO-stratosphere teleconnection $(\mathrm{Hu}$ et al. 2017; Domeisen et al. 2019) cannot be explained by the PDO.

Although the "pure" atmospheric PDO components are calculated differently between our study and Kren et al. (2016), the stratospheric response patterns are quite consistent (see Fig. 6 in Kren et al. 2016). Kren et al. (2016) selected the PDO events when ENSO is neutral from a model, while our study uses a positiveminus-negative difference for the PDO to filter out the tropical ENSO SST forcing from the CMIP5 MME. It can be inferred that the PDO might linearly interfere with the ENSO forcing to modify the ENSO-stratosphere relationship.

The specific mechanism whereby the PDO modulates the extratropical tropospheric response is beyond the scope of this study. We speculate that if the meridional SST gradient is enhanced (e.g., in $\mathrm{El} / \mathrm{P}$ winters), the tropospheric atmospheric baroclinicity may increase, accounting for the strengthened extratropical response. The cold SST anomalies in the North Pacific that usually accompany El Niño during the positive PDO can be reversed during the negative $\mathrm{PDO}$, which results in a weaker SST meridional gradient anomaly between the tropical and North Pacific.

Our study also confirms that the stratospheric responses are nearly symmetric between El/P winters and $\mathrm{La} / \mathrm{N}$ winters as the sample size becomes large (Garfinkel et al. 2018). The asymmetric response of the stratospheric temperature to ENSO in some other studies might be affected by the atmospheric internal noise when the ENSO sample size is less than 30 (Rao and Ren 2016b,c; Xie et al. 2018; Garfinkel et al. 2018). The El Niño SST pattern over the equatorial Pacific might also contribute to the change in the amplitude of the impact of El Niño on the stratosphere. In the last decades there has been an increase in the number of $\mathrm{CP}$ El Niño events, which have a weaker impact on the stratosphere on average. Our MME results show that CP El Niño events have a weaker impact than EP El Niño events during the positive PDO (Calvo et al. 2017), but the EP events occur more frequently than CP events, in both positive and negative PDO phases in the CMIP5 MME.

The PDO has switched signs in the late 1970s and late 1990s, but the ENSO-vortex relationship was stronger prior to the late 1970s and has weakened since (Domeisen et al. 2019). Hence the timing of changes in PDO phase does not align with the timing of changes in the relationship between ENSO and the Arctic polar stratosphere. This inconsistency between observed decadal variability and the decadal variability implied by our findings suggests that the PDO cannot explain 
(or at least is not the primary factor for) the decadal change of the ENSO-stratosphere relationship. Actually, the PDO is not the only SST mode that can modulate the decadal change of ENSO teleconnections. The Atlantic multidecadal oscillation has been reported to affect the tropospheric ENSO impact on the global climate (López-Parages et al. 2015, 2016; Ayarzagüena et al. 2019). In addition to the oceanic variability, atmospheric modulation might also play a role for the nonstationarity of ENSO teleconnections. The QBO may also have contributed to the modified ENSO teleconnections (Garfinkel and Hartmann 2007; Wei et al. 2007; Rao and Ren 2017, 2018; Domeisen et al. 2019). Easterly QBO coincided with El Niño and westerly QBO occurred preferentially during La Niña before 1979, but since then the phase coincidence of ENSO and QBO has been reversed, and this tendency may have also contributed to observed decadal variability (Domeisen et al. 2019). More models with QBO-like signals are expected to participate in the CMIP6, and the decadal modulation of the ENSO-stratosphere relationship by QBO also deserves a thorough investigation with CMIP6 outputs in the future.

Acknowledgments. JR and RCR were funded by the National Natural Science Foundation of China (41705024), the Strategic Priority Research Program of Chinese Academy of Sciences (XDA17010105), and the National Key R\&D Program of China (2016YFA0602104). CIG was supported by the Israel Science Foundation (1558/14) and the European Research Council starting grant under the European Union's Horizon 2020 research and innovation programme (677756). We acknowledge the ESGF for providing the CMIP5 (https://esgf-node.llnl.gov/ projects/esgf-llnl/) data.

\section{REFERENCES}

Alexander, M. A., 2010: Extratropical air-sea interaction, sea surface temperature variability, and the Pacific decadal oscillation. Climate Dynamics: Why Does Climate Vary? Geophys. Monogr., Vol. 189, Amer. Geophys. Union, 123148.

- and Coauthors, 2006: Extratropical atmosphere-ocean variability in CCSM3. J. Climate, 19, 2496-2525, https://doi.org/ 10.1175/JCLI3743.1.

Andrews, D. G., J. R. Holton, and C. B. Leovy, 1987: Middle Atmosphere Dynamics. Academic Press, 489 pp.

Annamalai, H., H. Okajima, and M. Watanabe, 2007: Possible impact of the Indian Ocean SST on the Northern Hemisphere circulation during El Niño. J. Climate, 20, 3164-3189, https:// doi.org/10.1175/JCLI4156.1.

Ashok, K., S. K. Behera, S. A. Rao, H. Weng, and T. Yamagata, 2007: El Niño Modoki and its possible teleconnection. J. Geophys. Res., 112, C11007, https://doi.org/10.1029/2006JC003798.
Ayarzagüena, B., S. Ineson, N. J. Dunstone, M. P. Baldwin, and A. A. Scaife, 2018: Intraseasonal effects of El Niño-Southern Oscillation on North Atlantic climate. J. Climate, 31, 88618873, https://doi.org/10.1175/JCLI-D-18-0097.1.

, J. López-Parages, M. Iza, N. Calvo, and B. RodríguezFonseca, 2019: Stratospheric role in interdecadal changes of El Niño impacts over Europe. Climate Dyn., 52, 1173-1186, https://doi.org/10.1007/s00382-018-4186-3.

Barnston, A. G., and R. E. Livezey, 1987: Classification, seasonality and persistence of low-frequency atmospheric circulation patterns. Mon. Wea. Rev., 115, 1083-1126, https://doi.org/ 10.1175/1520-0493(1987)115<1083:CSAPOL > 2.0.CO;2.

Barriopedro, D., and N. Calvo, 2014: On the relationship between ENSO, stratospheric sudden warmings, and blocking. J. Climate, 27, 4704-4720, https://doi.org/10.1175/JCLI-D-1300770.1.

Bell, C. J., L. J. Gray, A. J. Charlton-Perez, M. M. Joshi, and A. A. Scaife, 2009: Stratospheric communication of El Niño teleconnections to European winter. J. Climate, 22, 4083-4096, https://doi.org/10.1175/2009JCLI2717.1.

Bond, N. A., and D. E. Harrison, 2000: The Pacific decadal oscillation, air-sea interaction and central north Pacific winter atmospheric regimes. Geophys. Res. Lett., 27, 731-734, https:// doi.org/10.1029/1999GL010847.

Brönnimann, S., E. Xoplaki, C. Casty, A. Pauling, and J. Luterbacher, 2006: ENSO influence on Europe during the last centuries. Climate Dyn., 28, 181-197, https://doi.org/10.1007/s00382-0060175-z.

Cagnazzo, C., and E. Manzini, 2009: Impact of the stratosphere on the winter tropospheric teleconnections between ENSO and the North Atlantic and European region. J. Climate, 22, 1223-1238, https://doi.org/10.1175/ 2008JCLI2549.1.

- and Coauthors, 2009: Northern winter stratospheric temperature and ozone responses to ENSO inferred from an ensemble of chemistry climate models. Atmos. Chem. Phys., 9, 8935-8948, https://doi.org/10.5194/acp-9-89352009.

Calvo, N., M. A. Giorgetta, R. Garcia-Herrera, and E. Manzini, 2009: Nonlinearity of the combined warm ENSO and QBO effects on the Northern Hemisphere polar vortex in MAECHAM5 simulations. J. Geophys. Res., 114, D13109, https:// doi.org/10.1029/2008JD011445.

— pathway of different El Niño flavors in stratosphere-resolving CMIP5 models. J. Climate, 30, 4351-4371, https://doi.org/ 10.1175/JCLI-D-16-0132.1.

Camp, C. D., and K.-K. Tung, 2007: Stratospheric polar warming by ENSO in winter: A statistical study. Geophys. Res. Lett., 34, L04809, https://doi.org/10.1029/2006GL028521.

Charlton-Perez, A. J., and Coauthors, 2013: On the lack of stratospheric dynamical variability in low-top versions of the CMIP5 models. J. Geophys. Res. Atmos., 118, 2494-2505, https://doi.org/10.1002/JGRD.50125.

Chhak, K. C., E. Di Lorenzo, N. Schneider, and P. F. Cummins, 2009: Forcing of low-frequency ocean variability in the northeast Pacific. J. Climate, 22, 1255-1276, https://doi.org/ 10.1175/2008JCLI2639.1.

Dai, A., 2013: The influence of the inter-decadal Pacific oscillation on US precipitation during 1923-2010. Climate Dyn., 41, 633646, https://doi.org/10.1007/s00382-012-1446-5.

Davini, P., C. Cagnazzo, P. G. Fogli, E. Manzini, S. Gualdi, and A. Navarra, 2014: European blocking and Atlantic jet stream 
variability in the NCEP/NCAR reanalysis and the CMCCCMS climate model. Climate Dyn., 43, 71-85, https://doi.org/ 10.1007/s00382-013-1873-y.

Deser, C., A. S. Phillips, and M. A. Alexander, 2010: Twentieth century tropical sea surface temperature trends revisited. Geophys. Res. Lett., 37, L10701, https://doi.org/10.1029/ 2010 GL043321.

_, and Coauthors, 2012: ENSO and Pacific decadal variability in the Community Climate System Model version 4. J. Climate, 25, 2622-2651, https://doi.org/10.1175/JCLI-D11-00301.1.

_ I. R. Simpson, K. A. McKinnon, and A. S. Phillips, 2017: The Northern Hemisphere extratropical atmospheric circulation response to ENSO: How well do we know it and how do we evaluate models accordingly? J. Climate, 30, 5059-5082, https://doi.org/10.1175/JCLI-D-16-0844.1.

Dettinger, M. D., D. S. Battisti, G. J. McCabe, C. M. Bitz, and R. D. Garreaud, 2001: Interhemispheric effects of interannual and decadal ENSO-like climate variations on the Americas. Interhemispheric Climate Linkages: Present and Past Climates in the Americas and their Societal Effects, V. Markgraf, Ed., Academic Press, 1-16.

Domeisen, D. I. V., A. H. Butler, K. Fröhlich, M. Bittner, W. Müller, and J. Baehr, 2015: Seasonal predictability over Europe arising from El Niño and stratospheric variability in the MPI-ESM Seasonal Prediction System. J. Climate, 28, 256271, https://doi.org/10.1175/JCLI-D-14-00207.1.

- C. I. Garfinkel, and A. H. Butler, 2019: The teleconnection of El Niño Southern Oscillation to the stratosphere. Rev. Geophys., 57, 5-47, https://doi.org/10.1029/2018RG000596.

Donner, L. J., and Coauthors, 2011: The dynamical core, physical parameterizations, and basic simulation characteristics of the atmospheric component AM3 of the GFDL global coupled model CM3. J. Climate, 24, 3484-3519, https://doi.org/10.1175/ 2011JCLI3955.1.

Dufresne, J. L., and Coauthors, 2013: Climate change projections using the IPSL-CM5 Earth system model: From CMIP3 to CMIP5. Climate Dyn., 40, 2123-2165, https://doi.org/10.1007/ s00382-012-1636-1.

Fletcher, C. G., and P. J. Kushner, 2011: The role of linear interference in the annular mode response to tropical SST forcing. J. Climate, 24, 778-794, https://doi.org/10.1175/2010JCLI3735.1.

Fogli, P. G., and D. Iovino, 2014: CMCC-CESM-NEMO: Toward the new CMCC Earth System Model (December 2014). CMCC Research Paper 248, 19 pp., https://doi.org/10.2139/ ssrn.2603176.

Frankignoul, C., and N. Sennéchael, 2007: Observed influence of North Pacific SST anomalies on the atmospheric circulation. J. Climate, 20, 592-606, https://doi.org/10.1175/JCLI4021.1.

Free, M., and D. J. Seidel, 2009: Observed El Niño-Southern Oscillation temperature signal in the stratosphere. J. Geophys. Res., 114, D23108, https://doi.org/10.1029/2009JD012420.

García-Herrera, R., N. Calvo, R. R. Garcia, and M. A. Giorgetta, 2006: Propagation of ENSO temperature signals into the middle atmosphere: A comparison of two general circulation models and ERA-40 reanalysis data. J. Geophys. Res., 111, D06101, https://doi.org/10.1029/ 2005JD006061.

Garfinkel, C. I., and D. L. Hartmann, 2007: Effects of the El Niño-Southern Oscillation and the Quasi-Biennial Oscillation on polar temperatures in the stratosphere. J. Geophys. Res., 112, D19112, https://doi.org/10.1029/ 2007JD008481.
— , and - 2008: Different ENSO teleconnections and their effects on the stratospheric polar vortex. J. Geophys. Res., 113, D18114, https://doi.org/10.1029/2008JD009920.

$\longrightarrow$, and - 2010: Influence of the quasi-biennial oscillation on the North Pacific and El Niño teleconnections. J. Geophys. Res., 115, D20116, https://doi.org/10.1029/2010JD014181.

,-- , and F. Sassi, 2010: Tropospheric precursors of anomalous Northern Hemisphere stratospheric polar vortices. J. Climate, 23, 3282-3299, https://doi.org/10.1175/ 2010JCLI3010.1.

— A. H. Butler, D. W. Waugh, M. M. Hurwitz, and L. M. Polvani, 2012: Why might stratospheric sudden warmings occur with similar frequency in El Niño and La Niña winters? J. Geophys. Res., 117, D19106, https://doi.org/10.1029/ 2012JD017777.

— M. M. Hurwitz, D. W. Waugh, and A. H. Butler, 2013: Are the teleconnections of central Pacific and eastern Pacific El Niño distinct in boreal wintertime? Climate Dyn., 41, 18351852, https://doi.org/10.1007/s00382-012-1570-2.

_ A. Gordon, L. D. Oman, F. Li, S. Davis, and S. Pawson, 2018: Nonlinear response of tropical lower-stratospheric ENSO. Atmos. Chem. Phys., 18, 4597-4615, https://doi.org/10.5194/ acp-18-4597-2018.

Gershunov, A., and T. P. Barnett, 1998: Interdecadal modulation of ENSO teleconnections. Bull. Amer. Meteor. Soc., 79, 2715-2726, https://doi.org/10.1175/1520-0477(1998)079<2715:IMOET>2.0. $\mathrm{CO} ; 2$.

Giorgetta, M. A., and Coauthors, 2013: Climate and carbon cycle changes from 1850 to 2100 in MPI-ESM simulations for the Coupled Model Intercomparison Project phase 5. J. Adv. Model. Earth Syst., 5, 572-597, https://doi.org/10.1002/ jame.20038.

Graf, H., and D. Zanchettin, 2012: Central Pacific El Niño, the subtropical bridge, and Eurasian climate. J. Geophys. Res. 117, D01102, https://doi.org/10.1029/2011JD016493.

Hegyi, B. M., Y. Deng, R. X. Black, and R. Zhou, 2014: Initial transient response of the winter polar stratospheric vortex to idealized equatorial Pacific sea surface temperature anomalies in the NCAR WACCM. J. Climate, 27, 2699-2713, https:// doi.org/10.1175/JCLI-D-13-00289.1.

Hu, D., and Z. Guan, 2018: Decadal relationship between the stratospheric Arctic vortex and Pacific decadal oscillation. J. Climate, 31, 3371-3386, https://doi.org/10.1175/JCLI-D-170266.1.

Hu, J., T. Li, H. Xu, and S. Yang, 2017: Lessened response of boreal winter stratospheric polar vortex to El Niño in recent decades. Climate Dyn., 49, 263-278, https://doi.org/10.1007/s00382-0163340-z.

Hurwitz, M. M., P. A. Newman, and C. I. Garfinkel, 2012: On the influence of North Pacific sea surface temperature on the Arctic winter climate. J. Geophys. Res., 117, D19110, https:// doi.org/10.1029/2012JD017819.

__ and Coauthors, 2014: Extra-tropical atmospheric response to ENSO in the CMIP5 models. Climate Dyn., 43, 3367-3376, https://doi.org/10.1007/s00382-014-2110-z.

Ineson, S., and A. A. Scaife, 2009: The role of the stratosphere in the European climate response to El Niño. Nat. Geosci., 2 , 32-36, https://doi.org/10.1038/ngeo381.

Iza, M., N. Calvo, and E. Manzini, 2016: The stratospheric pathway of La Niña. J. Climate, 29, 8899-8914, https://doi.org/10.1175/ JCLI-D-16-0230.1.

Jadin, E. A., K. Wei, Y. A. Zyulyaeva, W. Chen, and L. Wang, 2010: Stratospheric wave activity and the Pacific Decadal 
Oscillation. J. Atmos. Sol.-Terr. Phys., 72, 1163-1170, https:// doi.org/10.1016/j.jastp.2010.07.009.

Jiménez-Esteve, B., and D. I. V. Domeisen, 2018: The tropospheric pathway of the ENSO-North Atlantic teleconnection. J. Climate, 31, 4563-4584, https://doi.org/10.1175/JCLI-D-17-0716.1.

Kalnay, E., and Coauthors, 1996: The NCEP/NCAR 40-Year Reanalysis Project. Bull. Amer. Meteor. Soc., 77, 437-471, https:// doi.org/10.1175/1520-0477(1996)077<0437:TNYRP >2.0.CO;2.

King, M. P., I. Herceg-Bulić, F. Kucharski, and N. Keenlyside, 2018: Interannual tropical Pacific sea surface temperature anomalies teleconnection to Northern Hemisphere atmosphere in November. Climate Dyn., 50, 1881-1899, https:// doi.org/10.1007/s00382-017-3727-5.

Kren, A. C., D. R. Marsh, A. K. Smith, and P. Pilewskie, 2016: Wintertime Northern Hemisphere response in the stratosphere to the Pacific decadal oscillation using the Whole Atmosphere Community Climate Model. J. Climate, 29, 10311049, https://doi.org/10.1175/JCLI-D-15-0176.1.

Kwon, Y.-O., and C. Deser, 2007: North Pacific decadal variability in the Community Climate System Model version 2. J. Climate, 20, 2416-2433, https://doi.org/10.1175/JCLI4103.1.

_, M. A. Alexander, N. A. Bond, C. Frankignoul, H. Nakamura, B. Qiu, and L. A. Thompson, 2010: Role of the Gulf Stream and Kuroshio-Oyashio systems in large-scale atmosphereocean interaction: A review. J. Climate, 23, 3249-3281, https:// doi.org/10.1175/2010JCLI3343.1.

Larkin, N. K., and D. E. Harrison, 2005: On the definition of El Niño and associated seasonal average U.S. weather anomalies. Geophys. Res. Lett., 32, L13705, https://doi.org/10.1029/ 2005 GL022738.

Li, Y., and N.-C. Lau, 2013: Influence of ENSO on stratospheric variability and the descent of stratospheric perturbations into the lower troposphere. J. Climate, 26, 4725-4748, https:// doi.org/10.1175/JCLI-D-12-00581.1.

Limpasuvan, V., D. L. Hartmann, D. W. J. Thompson, K. Jeev, and Y. L. Yung, 2005: Stratosphere-troposphere evolution during polar vortex intensification. J. Geophys. Res., 110, D24101, https://doi.org/10.1029/2005JD006302.

López-Parages, J., B. Rodríguez-Fonseca, and L. Terray, 2015: A mechanism for the multidecadal modulation of ENSO teleconnection with Europe. Climate Dyn., 45, 867-880, https:// doi.org/10.1007/s00382-014-2319-x.

,-- E. Mohino, and T. Losada, 2016: Multidecadal modulation of ENSO teleconnection with Europe in late winter: Analysis of CMIP5 models. J. Climate, 29, 8067-8081, https:// doi.org/10.1175/JCLI-D-15-0596.1.

Mantua, N. J., and S. R. Hare, 2002: The Pacific Decadal Oscillation. J. Oceanogr., 58, 35-44, https://doi.org/10.1023/ A:1015820616384.

— - — , Y. Zhang, J. M. Wallace, and R. C. Francis, 1997: A Pacific interdecadal climate oscillation with impacts on salmon production. Bull. Amer. Meteor. Soc., 78, 1069-1079, https:// doi.org/10.1175/1520-0477(1997)078<1069:APICOW>2.0.CO;2.

Manzini, E., M. A. Giorgetta, M. Esch, L. Kornblueh, and E. Roeckner, 2006: The influence of sea surface temperatures on the northern winter stratosphere: Ensemble simulations with the MAECHAM5 model. J. Climate, 19, 3863-3881, https://doi.org/10.1175/JCLI3826.1.

Marsh, D. R., R. R. Garcia, D. E. Kinnison, B. A. Boville, F. Sassi, S. C. Solomon, and K. Matthes, 2007: Modeling the whole atmosphere response to solar cycle changes in radiative and geomagnetic forcing. J. Geophys. Res., 112, D23306, https:// doi.org/10.1029/2006JD008306.
- M. J. Mills, D. E. Kinnison, J. F. Lamarque, N. Calvo, and L. M. Polvani, 2013: Climate change from 1850 to 2005 simulated in CESM1(WACCM). J. Climate, 26, 7372-7391, https://doi.org/10.1175/JCLI-D-12-00558.1.

Martin, G. M., and Coauthors, 2011: The HadGEM2 family of Met Office Unified Model climate configurations. Geosci. Model Dev., 4, 723-757, https://doi.org/10.5194/gmd-4-723-2011.

Matthes, K., D. R. Marsh, R. R. Garcia, D. E. Kinnison, F. Sassi, and S. Walters, 2010: Role of the QBO in modulating the influence of the 11 year solar cycle on the atmosphere using constant forcings. J. Geophys. Res., 115, D18110, https://doi.org/ 10.1029/2009JD013020.

Meehl, G. A., and H. Y. Teng, 2007: Multi-model changes in El Niño teleconnections over North America in a future warmer climate. Climate Dyn., 29, 779-790, https://doi.org/10.1007/ s00382-007-0268-3.

Mills, C. M., and J. E. Walsh, 2013: Seasonal variation and spatial patterns of the atmospheric component of the Pacific decadal oscillation. J. Climate, 26, 1575-1594, https://doi.org/10.1175/ JCLI-D-12-00264.1.

Minobe, S., 1997: A 50-70 year climatic oscillation over the North Pacific and North America. Geophys. Res. Lett., 24, 683-686, https://doi.org/10.1029/97GL00504.

Newman, M., G. P. Compo, and M. A. Alexander, 2003: ENSOforced variability of the Pacific decadal oscillation. J. Climate, 16, 3853-3857, https://doi.org/10.1175/1520-0442(2003)016<3853: EVOTPD $>2.0 . \mathrm{CO} ; 2$.

, and Coauthors, 2016: The Pacific Decadal Oscillation, revisited. J. Climate, 29, 4399-4427, https://doi.org/10.1175/ JCLI-D-15-0508.1.

Nishii, K., H. Nakamura, and Y. J. Orsolini, 2010: Cooling of the wintertime Arctic stratosphere induced by the western Pacific teleconnection pattern. Geophys. Res. Lett., 37, L13805, https:// doi.org/10.1029/2010GL043551.

Papineau, J. M., 2001: Wintertime temperature anomalies in Alaska correlated with ENSO and PDO. Int. J. Climatol., 21, 1577-1592, https://doi.org/10.1002/joc.686.

Pavia, E. G., F. Graef, and J. Reyes, 2006: PDO-ENSO effects in the climate of Mexico. J. Climate, 19, 6433-6438, https://doi.org/10.1175/ JCLI4045.1.

Plumb, R. A., 1985: On the three-dimensional propagation of stationary waves. J. Atmos. Sci., 42, 217-229, https://doi.org/ 10.1175/1520-0469(1985)042<0217:OTTDPO > 2.0.CO;2.

Polvani, L. M., L. Sun, A. H. Butler, J. H. Richter, and C. Deser, 2017: Distinguishing stratospheric sudden warmings from ENSO as key drivers of wintertime climate variability over the North Atlantic and Eurasia. J. Climate, 30, 1959-1969, https:// doi.org/10.1175/JCLI-D-16-0277.1.

Rao, J., and R. Ren, 2014: Statistical characteristics of ENSO events in CMIP5 models. Atmos. Oceanic Sci. Lett., 7, 546552, https://doi.org/10.3878/AOSL20140055.

—, and 2016a: A decomposition of ENSO's impacts on the northern winter stratosphere: Competing effect of SST forcing in the tropical Indian Ocean. Climate Dyn., 46, 36893707, https://doi.org/10.1007/s00382-015-2797-5.

— , and _ 2016b: Asymmetry and nonlinearity of the influence of ENSO on the northern winter stratosphere: $1 . \mathrm{Ob}-$ servations. J. Geophys. Res. Atmos., 121, 9000-9016, https:// doi.org/10.1002/2015JD024520.

, and - 2016c: Asymmetry and nonlinearity of the influence of ENSO on the northern winter stratosphere: 2. Model study with WACCM. J. Geophys. Res., 121, 9017-9032, https:// doi.org/10.1002/2015JD024521. 
and - 2017: Parallel comparison of the 1982/83, 1997/98, and 2015/16 super El Niños and their effects on the extratropical stratosphere. Adv. Atmos. Sci., 34, 1121-1133, https:// doi.org/10.1007/s00376-017-6260-x.

, and _ 2018: Varying stratospheric responses to tropical Atlantic SST forcing from early to late winter. Climate Dyn., 51, 2079-2096, https://doi.org/10.1007/s00382-017-3998-x.

, - - and Y. Yang, 2015: Parallel comparison of the northern winter stratospheric circulation in reanalysis and in CMIP5 models. Adv. Atmos. Sci., 32, 952-966, https://doi.org/10.1007/ s00376-014-4192-2.

,,-- X. Xia, C. Shi, and D. Guo, 2019: Combined impact of El Niño-Southern Oscillation and Pacific Decadal Oscillation on the northern winter stratosphere. Atmosphere, 10, 211, https://doi.org/10.3390/atmos10040211.

Rayner, N. A., and Coauthors, 2003: Global analyses of sea surface temperature, sea ice, and night marine air temperature since the late nineteenth century. J. Geophys. Res., 108, 4407, https://doi.org/10.1029/2002JD002670.

Ren, R., J. Rao, G. Wu, and M. Cai, 2017: Tracking the delayed response of the northern winter stratosphere to ENSO using multi reanalyses and model simulations. Climate Dyn., 48, 2859-2879, https://doi.org/10.1007/s00382-016-3238-9.

Sassi, F., D. Kinnison, B. A. Boville, R. R. Garcia, and R. Roble, 2004: Effect of El Niño-Southern Oscillation on the dynamical, thermal, and chemical structure of the middle atmosphere. J. Geophys. Res., 109, D17108, https://doi.org/10.1029/ 2003JD004434.

Schneider, N., and B. D. Cornuelle, 2005: The forcing of the Pacific decadal oscillation. J. Climate, 18, 4355-4373, https://doi.org/ 10.1175/JCLI3527.1.

Schoennagel, T., T. T. Veblen, W. H. Romme, J. S. Sibold, and E. R. Cook, 2005: ENSO and PDO variability affect drought-induced fire occurrence in Rocky Mountain subalpine forests. Ecol. Appl., 15, 2000-2014, https://doi.org/ 10.1890/04-1579.

Seager, R., Y. Kushnir, P. Chang, N. Naik, J. Miller, and W. Hazeleger, 2001: Looking for the role of the ocean in tropical Atlantic decadal climate variability. J. Climate, 14, 638-655, https://doi.org/10.1175/1520-0442(2001)014<0638: LFTROT>2.0.CO;2.

Shakun, J. D., and J. Shaman, 2009: Tropical origins of North and South Pacific decadal variability. Geophys. Res. Lett., 36, L19711, https://doi.org/10.1029/2009GL040313.

Smith, K. L., and P. J. Kushner, 2012: Linear interference and the initiation of extratropical stratosphere-troposphere interactions. J. Geophys. Res., 117, D13107, https://doi.org/ 10.1029/2012JD017587.

— C. C. Fletcher, and P. J. Kushner, 2010: The role of linear interference in the annular mode response to extratropical surface forcing. J. Climate, 23, 6036-6050, https://doi.org/ 10.1175/2010JCLI3606.1.

Song, K., and S.-W. Son, 2018: Revisiting the ENSO-SSW relationship. J. Climate, 31, 2133-2143, https://doi.org/10.1175/ JCLI-D-17-0078.1.

Sung, M.-K., B.-M. Kim, and S.-I. An, 2014: Altered atmospheric responses to eastern Pacific and central Pacific El Niños over the North Atlantic region due to stratospheric interference. Climate Dyn., 42, 159-170, https://doi.org/10.1007/s00382-012-1661-0.

Taguchi, M., and D. L. Hartmann, 2006: Increased occurrence of stratospheric sudden warmings during El Niño as simulated by WACCM. J. Climate, 19, 324-332, https://doi.org/10.1175/ JCLI3655.1.
Taylor, K. E., R. J. Stouffer, and G. A. Meehl, 2012: An overview of CMIP5 and the experiment design. Bull. Amer. Meteor. Soc., 93, 485-498, https://doi.org/10.1175/BAMS-D-11-00094.1.

Tilmes, S., R. R. Garcia, D. E. Kinnison, A. Gettelman, and P. J. Rasch, 2009: Impact of geoengineered aerosols on the troposphere and stratosphere. J. Geophys. Res., 114, D12305, https://doi.org/10.1029/2008JD011420.

Tweedy, O. V., D. W. Waugh, W. J. Randel, M. Abalos, L. D. Oman, and D. E. Kinnison, 2018: The impact of boreal summer ENSO events on tropical lower stratospheric ozone. J. Geophys. Res., 123, 9843-9857, https://doi.org/10.1029/2018JD029020.

Veettil, B. K., E. L. B. Maier, U. F. Bremer, and S. F. de Souza, 2014: Combined influence of PDO and ENSO on northern Andean glaciers: A case study on the Cotopaxi ice-covered volcano, Ecuador. Climate Dyn., 43, 3439-3448, https:// doi.org/10.1007/s00382-014-2114-8.

Wallace, J. M., and D. S. Gutzler, 1981: Teleconnections in the geopotential height field during the Northern Hemisphere winter. Mon. Wea. Rev., 109, 784-812, https://doi.org/10.1175/ 1520-0493(1981)109<0784:TITGHF $>2.0 . \mathrm{CO} ; 2$.

Watanabe, S., and Coauthors, 2011: MIROC-ESM 2010: Model description and basic results of CMIP5-20c3m experiments. Geosci. Model Dev., 4, 845-872, https://doi.org/10.5194/gmd-4-845-2011.

Wei, K., W. Chen, and R. Huang, 2007: Association of tropical Pacific sea surface temperatures with the stratospheric Holton-Tan Oscillation in the Northern Hemisphere winter. Geophys. Res. Lett., 34, L16814, https://doi.org/10.1029/2007GL030478.

Weinberger, I., C. I. Garfinkel, I. P. White, and L. Oman, 2019: The salience of nonlinearities in the boreal winter response to ENSO: Arctic stratosphere and Europe. Climate Dyn., https:// doi.org/10.1007/S00382-019-04805-1.

Wittenberg, A. T., 2009: Are historical records sufficient to constrain ENSO simulations? Geophys. Res. Lett., 36, L12702, https://doi.org/10.1029/2009GL038710.

Woo, S.-H., M.-K. Sung, S.-W. Son, and J.-S. Kug, 2015: Connection between weak stratospheric vortex events and the Pacific Decadal Oscillation. Climate Dyn., 45, 3481-3492, https:// doi.org/10.1007/s00382-015-2551-z.

$\mathrm{Wu}, \mathrm{X}$., and J. Mao, 2016: Interdecadal modulation of ENSOrelated spring rainfall over South China by the Pacific Decadal Oscillation. Climate Dyn., 47, 3203-3220, https://doi.org/ 10.1007/s00382-016-3021-y.

Xiao, M., Q. Zhang, and V. P. Singh, 2015: Influences of ENSO, NAO, IOD and PDO on seasonal precipitation regimes in the Yangtze River basin, China. Int. J. Climatol., 35, 3556-3567, https://doi.org/10.1002/joc.4228.

Xie, F., J. Li, W. Tian, J. Feng, and Y. Huo, 2012: Signals of El Niño Modoki in the tropical tropopause layer and stratosphere. Atmos. Chem. Phys., 12, 5259-5273, https://doi.org/10.5194/ acp-12-5259-2012.

_ - X. Zhou, J. Li, C. Sun, J. Feng, and X. Ma, 2018: The key role of background sea surface temperature over the cold tongue in asymmetric responses of the Arctic stratosphere to El NiñoSouthern Oscillation. Environ. Res. Lett., 13, L14007, https:// doi.org/10.1088/1748-9326/aae79b.

Yang, S., T. Li, J. Hu, and X. Shen, 2017: Decadal variation of the impact of La Niña on the winter Arctic stratosphere. Adv. Atmos. Sci., 34, 679-684, https://doi.org/10.1007/s00376-016-6184-x.

Yu, B., and F. W. Zwiers, 2007: The impact of combined ENSO and PDO on the PNA climate: A 1000-year climate modeling study. Climate Dyn., 29, 837-851, https://doi.org/10.1007/s00382-007-0267-4.

Yu, J.-Y., and S. T. Kim, 2011: Relationships between extratropical sea level pressure variations and the central Pacific and 
eastern Pacific types of ENSO. J. Climate, 24, 708-720, https:// doi.org/10.1175/2010JCLI3688.1.

Yukimoto, S., and Coauthors, 2012: A new global climate model of the Meteorological Research Institute: MRI-CGCM3, model description and basic performance. J. Meteor. Soc. Japan, $\mathbf{9 0 A}$, 23-64, https://doi.org/10.2151/jmsj.2012-A02.

Zanchettin, D., S. W. Franks, P. Traverso, and M. Tomasino, 2008: On ENSO impacts on European wintertime rainfalls and their modulation by the NAO and the Pacific multidecadal variability described through the PDO index. Int. J. Climatol., 28, 995-1006, https://doi.org/10.1002/ joc. 1601 .

Zhang, Y., J. M. Wallace, and D. S. Battisti, 1997: ENSO-like interdecadal variability: 1900-93. J. Climate, 10,
1004-1020, https://doi.org/10.1175/1520-0442(1997)010<1004: ELIV>2.0.CO;2.

Zhao, X., J. Rao, and J. Mao, 2019: The salient differences in China summer rainfall response to ENSO: Phases, intensities and flavors. Climate Res., 78, 51-67, https://doi.org/10.3354/ cr01560.

Zhou, X., J. Li, F. Xie, R. Ding, Y. Li, S. Zhao, J. Zhang, and Y. Li, 2018: The effects of the Indo-Pacific warm pool on the stratosphere. Climate Dyn., 51, 4043-4064, https://doi.org/ 10.1007/s00382-017-3584-2.

Zhou, Z., S. Xie, X. Zheng, Q. Liu, and H. Wang, 2014: Global warming-induced changes in El Niño teleconnections over the North Pacific and North America. J. Climate, 27, 9050-9064, https://doi.org/10.1175/JCLI-D-14-00254.1. 